
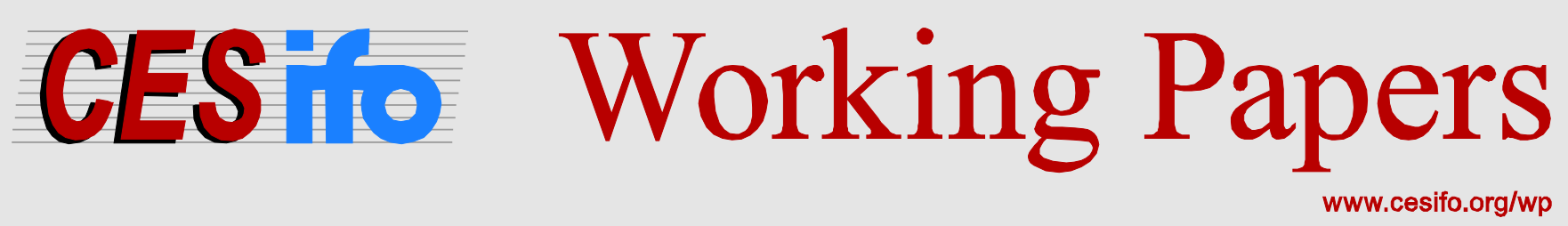

\title{
Globalization, Wage Polarization, and the Unstable Great Ratio
}

\author{
Guido Cozzi \\ Giammario Impullitti
}

\author{
CESIFO WORKING PAPER NO. 5031 \\ CATEgory 6: Fiscal POLICY, MACROECONOMICS AND GROWTH \\ OCTOBER 2014
}
An electronic version of the paper may be downloaded
- from the SSRN website:
- from the RePEc website:
- from the CESifo website:
www.SSRN.com
Www.RePEc.org
www.CESifo-group.org/wp

\section{CESifo}




\title{
Globalization, Wage Polarization, and the Unstable Great Ratio
}

\begin{abstract}
The US labour market has experienced a remarkable polarization in the 1980s and 1990s. Moreover, recent empirical work has documented a sharp increase in the wealth to income ratio in that period. Contemporary to these inequality trends, the US faced a fast technological catch-up as European countries and especially Japan drastically improved their global innovation and patenting activity. Is foreign technological convergence an important source of the recent evolution of the US wage and employment structure? Can it contribute shaping the dynamics of wealth-to-income ratio? To answer these questions, we set up a Schumpeterian model of endogenous technological progress with two asymmetric countries, heterogeneous workers, and endogenous skill formation. High ability people acquire education and become skilled, those with intermediate abilities work as unskilled workers in production jobs, and those at the bottom of the ability distribution work in service occupations. Service workers provide personal services allowing their employers to save working time. In equilibrium, only skilled workers buy personal services. Fiercer foreign competition triggered by technological catching up shifts production jobs abroad and forces domestic firms to innovate more. Hence, the employment share of production workers shrinks, while the demand for both high skilled and service sector workers rises, thus increasing polarization. Calibrating the model to match key facts of the US economy, we find that foreign technological catching-up observed between the late 1970s and early 1990s reproduces a non-negligible part of US wage polarization and substantial part of the increase in the wealth-to-income ratio in that period.
\end{abstract}

JEL-Code: F160, J310, O330.

Keywords: wage polarization, heterogeneous workers, wealth-income ratio, endogenous technical change, international technology competition, personal service sector.

Guido Cozzi

School of Economics and Political Science

University of St. Gallen / Switzerland

guido.cozzi@unisg.ch
Giammario Impullitti

School of Economics

University of Nottingham / UK

Giammario.Impullitti@nottingham.ac.uk

October 1, 2014 


\section{Introduction}

The US labour market has experienced a radical polarization of employment and wages in the last decades. In the 1980s and 1990s, both wages and employment shares at the tails of the skill distribution have grown steadily. Workers in the middle of the distribution instead have faced stagnant wages and a shrinking employment share (Acemoglu and Autor, 2011). Recent empirical work has shown that another pivotal distributional statistics, the capital/wealth to income ratio, has been increasing steadily since the mid-1970s in the US (Piketty, 2014 and Piketty and Zucman, 2014). For a long time, the capital-income ratio, together with the other

"great ratios", the labour and capital shares of income, were considered stable over the long run. The findings by Piketty and co-authors have brought new life to the analysis of the evolution of the great ratios. In line with the overall debate on inequality, technological progress has been considered a key source of several dimensions of inequality in the US and elsewhere. The literature is silent though regarding the potential sources of technical accelerations driving wage polarization and the capital-income ratio dynamics. To fill this gap, we explore the role of globalization, in the form of fiercer foreign technological competition, in shaping the recent evolution of the wage structure and the wealth to income ratio in the United States.

In those years of expanding labour market polarization, the US economy became increasingly globalized. The massive reduction in trade barriers and the diffusion of technologies across countries' borders allowed foreign firms, mostly from Japan and Europe, to challenge US technological leadership. The geography of technological leadership, measured as countries' share of innovation inputs and outputs, shows remarkable changes between the mid-70s and the late 1980s. From a distribution of leadership drastically skewed toward the US, to a more equal global playing field. Clear convergence patterns can be observed in the share of patents, patent citations and R\&D spending. The share of foreign patents in the US Patent Office, is about one third in 1977 and grows to about one half ten years later. The US share of global industrial R\&D declines from about 50 percent in 1979 to 39 percent in 1995. Most of this technological catching-up is due to a massive acceleration in Japanese innovation activity, although some European countries, such as Germany and France, played a major role in some sectors (Impullitti, 2010, and Akcigit, Ates, and Impullitti, 2014).

Did the acceleration of foreign technological competition in the 1980s contribute to the polarization of the US labour market? To answer this question we construct a quality ladder growth model (Aghion and Howitt, 1992, and Grossman and Helpman, 1991) with two asymmetric countries and heterogeneous workers. Firms compete for global market leadership investing in quality-improving innovation. Schumpeterian competition for innovation allows successful innovators to replace incumbents. The asymmetry between countries is represented by a technology gap in innovation: firms in the leading country have a better innovation technology in all sectors of the economy. There are three occupations: innovation, production, and services: innovation workers are employed in the production of new ideas to improve the 
quality of the goods produced by their firms. Blue collar/production workers are employed in manufacturing the goods. Service sector workers provide personal services that allow their employer to save working time. Workers have heterogeneous ability and they can acquire working skills through education. Education attainment allows workers to become skilled and work in innovation activities. Workers who do not acquire education can work as unskilled production workers or in service occupations.

In equilibrium, the following allocation of abilities to occupations obtains: workers with high innate ability become skilled and hire service sector workers, those with intermediate ability work in production occupations and finally, those at the bottom of the ability distribution work in personal service occupations. An exogenous reduction in the technology gap affects the leading economy innovation and labour market structure as follows: first, as foreign firms start innovating more efficiently, they obtain quality leadership in more sectors, thereby stealing market shares from firms in the leading country, forcing them to reduce the demand of production workers. This typical Schumpeterian business-stealing effect reduces wages of production workers in the leading economy. Second, the reduction in the technology gap makes it harder for domestic firms to innovate in the global economy, thus pushing them to devote more labour resources to innovation. This global competition effect triggers an increase in the demand for skilled workers. Via these two channels, increasing foreign competition generates more polarization in the leading economy's labour market: the wage of skilled workers relative to that of production workers increases, thereby raising inequality at the top of the skill distribution. The wage of service sector workers relative to that of production workers increases, thus reducing inequality at the bottom of the distribution. The increase in the demand and wages of service sector workers is a by-product of rising inequality at the top of the distribution. As skilled labour time becomes more valuable, skilled workers demand more personal services in order to free time to devote to their highly remunerative job.

Another key prediction of our model is the positive link between foreign technological competition, innovation, and the wealth to income ratio. The business-stealing and the global competition effects of foreign technological catching up increase the value of innovation in the global economy. The value of innovation in our framework is determined by the value of the leading firm in each product line, and aggregate wealth consists in the sum of the market values of all firms. Hence, our Schumpeterian economy predicts a natural connection between innovation, technological accelerations, growth, and the dynamics of the wealth to income ratio.

In an extended version of the model, we allow for a more general technology where skilled and unskilled workers are employed in production and innovation with different factor intensities, and we introduce iceberg trade costs. We then calibrate this generalized model and use it to explore the link between the technology gap, labour market polarization and the wealth to income ratio quantitatively. In our two-country world, the US is the leading economy and the rest of the world represents the foreign country. The technology gap between countries is calibrated to reproduce the distribution of patents in the US Patent Office observed in the 
data. Our quantitative exercise involves reducing the innovation technology gap to reproduce the convergence in US and foreign patent shares shown in the data between 1980 and 2000. We then compare the increase in polarization triggered by this reduction in the technology gap with that observed in the data, and find that our model can replicate about $13 \%$ of the increase in inequality at the top of the distribution, $26 \%$ of the increase in the skill premium, and about $23 \%$ of the decrease in inequality at the bottom observed between 1980 and 2000. Finally, the decline in the technology gap generates a striking increase in the US wealth to income ratio, reproducing a substantial part of the increase documented by Piketty and co-authors in this period.

The recent empirical evidence on labour market polarization in the US and other countries has triggered a new line of research aimed at understanding and interpreting these facts. Autor and Dorn (2013) present a simple "task-based" model formalizing the so-called "routinization" hypothesis. Technological progress is exogenous and is modelled as a decline in the costs of computerizing routine tasks. Hence, technical change replaces routine tasks workers, which are unskilled workers in the middle of the skill distribution. Moreover, routine task-replacing technical change is complementary to abstract, creative, problem solving activities performed by highly educated workers. Finally, service occupations are performed by uneducated workers at the bottom of the skill distribution, which new technology neither directly complements nor substitutes. By replacing routine tasks, technical change reduces the demand and wage for workers in the middle of the skill distribution, reallocating workers to service occupations. Moreover, complementarity between new technology and high skills increases the demand and wages at the right tail of the distribution ${ }^{1}$. Autor and Dorn test their prediction using US local labour markets data and find that locations specialized in routine tasks occupations experienced a wider introduction of computers in the workplace and a stronger reduction in routine intensive jobs in the 1980s and 1990s. They also find that employment and wages in low-skill service occupations increase.

In Autor and Dorn's model, technological progress and the supply of skills are exogenous. We complement their analysis by endogenizing both technological change and skill formation. In our economy, the introduction of new technologies is driven by profit incentives, and foreign technological competition is a key source of technological accelerations. Moreover, an education choice allows workers to transform their innate abilities into marketable skills. An additional fundametnal departure of our model from the task-based approach is that our theory provides a different mechanism linking technical change and the wage structure. New technologies do not replace mid-skilled routine workers by construction, thereby triggering workers reallocations toward service occupations. In our Schumpeterian framework, faster technological progress increases inequality at the top of the distribution: the business-stealing and the competition effect lead to a reduction in unskilled and an increase in skilled wages. As skilled wages raise,

\footnotetext{
${ }^{1}$ This capital skill-complementarity idea was first introduced by Krusell, Ohanian, Rios-Rull and Violante (2000) to study the evolution of the US skill premium in a two-skill model.
} 
skilled workers hire more personal service workers to devote more time to their higly paid jobs. This mechanism finds direct empirical support in Mazzolari and Ragusa (2013) who, using US city-level data, show that the increase in the top wages bill can explain about one-third of the growth of employment of non-college workers in low-skill personal services in the 1990s.

Our paper is also related to the literature focusing on globalization as a source wage inequality. A large body of work has studied the effects of trade liberalization on wage inequality across workers with different skills when technology is constant (e.g. Yeaple, 2005, Epifani and Gancia, 2008, Burnstein and Vogel, 2010), or when technology is endogenous and interacts with trade in shaping the wage structure (e.g. Dinopoulos and Segerstrom, 1999, Acemoglu, 2003, Thoenig and Verdier, 2003). We depart from this literature along two main lines: first, while existing papers focus on economies with two skills and explain the evolution of the skilled-unskilled wage gap, the skill premium, we set up a framework with a continuum of skills allocated to three occupations to study the dynamics of wage inequality in the middle and in the tails of the distribution. Second, we move from a widely studied dimension of globalization, trade liberalization, to the less explored channel of cross-country technological catch up. A small emerging literature has started to analyse the welfare effects on leading economies of foreign technological catching up (e.g. Eaton and Kortum, 2007, Hsie and Ossa, 2011, Impullitti, 2010, Akcigit, Ates, and Impullitti, 2014). Our paper contributes to this line of research studying the effects of foreign catching up on the structure of wages, employment, and on the evolution of the wealth to income ratio.

Finally, we contribute to the recent discussion on the evolution of the wealth-to-income ratio started by Piketty (2014) and Piketty and Zucman (2014) (e.g. Krusell and Smith, 2014, Acemoglu and Robinson, 2014, Jones, 2014). Piketty's provocative explanation for this empirical findings is based on the idea that most micro-funded economic models predict that the wealth (and the capital) to income ratio converges to $s / g$, where $s$ is the saving rate net of wealth depreciation and $g$ is economy's growth rate inclusive of population growth. Piketty (2014) calls this equation the "second law of capitalism" and uses it to predict a bleak future where slower technological progress and population growth pave the way to a world where accumulated past wealth grows disproportionately faster than income. We derive a Schumpeterian version of Piketty's "Law" and show that in our economy innovation-driven growth accelerations lead to higher wealth to income ratios. Hence, differently from Piketty's results, our endogenous growth model predicts a positive link between technological progress and the wealth-income ratio. We also show that this new link can be quantitatively important.

Our paper is organized as follows: Section 2 shows the stylized facts that motivate the paper. Section 3 sets up our baseline model; Section 4 characterizes its steady state equilibrium and Section 5 analytically derives its comparative statics properties. Section 6 is devoted to extending the model to match empirical regularities of the US economy and use it for a quantitative assessment of our theory. Section 7 concludes. 


\section{Stylized facts}

In this section, we discuss some key facts providing the motivation for the paper as well as the empirical support for the quantitative analysis.

Wage polarization. Since the early 1980s, the US shows a remarkable increase in labor market polarization. The distribution of wages and employment shares across workers with different skill levels becomes more unequal in the period between 1980 and the current times. Autor and Dorn (2013) document a non-monotonic change in employment and wages along the skill distribution. Working with Census IPUMS and American Community Survey data, they rank 318 occupations in all US nonfarm employment by skill level using the average log wages of workers in each occupation. Their results show that employment changes in the period 19802005 have an inverted U-shaped pattern. Employment in the middle of the skill distribution declines substantially, while the tails show a steady and somewhat puzzling increase. Digging deeper into the occupational structure of these changes they document that most of the increase in employment and wages in the lower tail can be attributed to one group of occupations that they name service occupations. These are low-education occupations involving caring, assisting and entertaining other people, such as, cleaners, janitors, security guards, food service workers, gardeners, home health aides, hairdressers, beauticians, and recreation occupations. Table 1 below shows the employment dynamics for three groups of occupations: the skilled workers, which include the occupations at the top of the skill distribution, the unskilled workers outside the service occupations, this is a low-educated occupational group including production and crafts jobs, operative and assembly occupations, transportation, construction, mechanical, mining, clerical and retails sales jobs. The third group is the service occupations described above. The data show a strong increase in the employment share of skilled workers, which grew by $25 \%$ between 1980 and 2000. Similarly, the employment share of service occupations increased by about $17 \%$ in the 1980-2000 period and by 30\% between 1980 and 2005. On the other hand, the employment share of unskilled non-service occupation declined by about $16 \%$ and $21 \%$ in the two periods considered. 
Table 1. Employment Share by Major Occupation Groups: 1970-2005

\begin{tabular}{llllllll}
\hline \hline & \multicolumn{2}{c}{ Levels } & & & \multicolumn{3}{c}{ growth } \\
& 1970 & 1980 & 1990 & 2000 & 2005 & $80-00$ & $80-05$ \\
\hline Skilled workers & 25.76 & 31.55 & 38.16 & 39.61 & 40.93 & 0.25 & 0.29 \\
\multicolumn{2}{c}{ Managers/Prof/Tech/Finance/Public Safety } & & & & & & \\
Unskill nO-service & 63.48 & 58.52 & 51.31 & 48.77 & 46.19 & -0.16 & -0.21 \\
Production/Craft & 5.05 & 4.82 & 4.78 & 3.54 & 2.97 & -0.23 & -0.37 \\
Transp/Constr/Mech/Mining/Farm & 22.2 & 21.5 & 18.7 & 18 & 18.2 & -0.16 & -0.15 \\
Machine Operators/Assemb1 & 13.1 & 9.94 & 7.30 & 5.70 & 4.60 & -0.42 & -0.53 \\
Clerical/Retail Sales & 23.1 & 22.2 & 21.6 & 21.4 & 20.3 & -0.04 & -0.08 \\
Unskill service & 10.74 & 9.91 & 10.51 & 11.61 & 12.87 & 0.17 & 0.30 \\
\hline \hline
\end{tabular}

Source: Autor and Dorn (2013)

Table 2 shows the levels and changes in wages for the three groups of occupations in the same period. We can see a substantial increase in wages of skilled workers and a smaller but non-negligible increase in service occupations' wages. The wages of unskilled workers in non-service occupations instead exhibit virtually no change in the last decades.

Table 2. Mean Real Hourly Wages by Major Occupation Groups: 1970-2005

\begin{tabular}{llllllll}
\hline \hline & \multicolumn{3}{l}{ Levels } & & \multicolumn{4}{c}{ growth } \\
& 1970 & 1980 & 1990 & 2000 & 2005 & $80-00$ & $80-05$ \\
\hline & \multicolumn{3}{l}{ Mean Log Hourly } & Wage $(2004 \$)$ \\
Skilled workers & 2.86 & 2.82 & 2.89 & 3.02 & 3.14 & 0.19 & 0.3 \\
Unskill no-service & 2.58 & 2.58 & 2.58 & 2.62 & 2.66 & 0.04 & 0.07 \\
Unskill service & 2.01 & 2.09 & 2.14 & 2.24 & 2.2 & 0.14 & 0.15 \\
& & & & & & & \\
Skilll Premium & 1.43 & 1.37 & 1.47 & 1.60 & 1.76 & 0.17 & 0.28 \\
Skill/Unskill(no serv) & 1.32 & 1.27 & 1.36 & 1.49 & 1.61 & 0.21 & 0.34 \\
Unskill(no serv)/Serv & 1.76 & 1.62 & 1.55 & 1.46 & 1.49 & -0.16 & -0.13 \\
\hline \hline
\end{tabular}

Source: Autor and Dorn (2013)

Focusing on the relative changes across these groups, we can look at the dynamics of the gap between the top and the middle of the distribution and that between the middle and the bottom. The first gap is represented by the ratio of skilled over unskilled (no-service) wages, which shows a $21 \%$ increase up to 2000 and a staggering $34 \%$ rise up to 2005 . The second gap is the ratio between the wages of unskilled workers outside personal service occupations and those of service workers. This ratio declines by 16 percentage points up to 2000 and by 13 points up to 2005. We have also computed a more standard measure of inequality, the skill premium, defined as the average wage of skilled workers over of the average wage of all unskilled workers, including service sectors workers. ${ }^{2}$ In line with inequality at the top of the distribution, the skill premium shows a remarkable increase after 1980 .

\footnotetext{
${ }^{2}$ The average unskilled wage is obtained using the employment shares of the unskilled (no service) and service occupation workers a weights.
} 
The wealth to income ratio. Building on a new, large, and rich data set, recent empirical work by Piketty (2014) and Piketty and Zucman (2014) have documented interesting and provocative facts about the dynamics and the distribution of income and wealth. Among the many key facts documented by their research, we chose to focus on one particular dimension of inequality, the wealth to income ratio. The wealth of a nation is defined as the sum of domestic capital plus net foreign assets. In an economy with a zero foreign assets position, the wealth to income ratio and domestic capital to income ratio coincide. For this reason, they use the terms wealth-income and capital-income ratio interchangeably. ${ }^{3}$ Piketty and Zucman (2014) report that the wealth to income ratio in the US rose from slightly above $300 \%$ in 1975 to $450 \%$ in 2000 and to almost $500 \%$ in 2007. Figure 2 shows the evolution of private wealth and its components in the period we are analysing. ${ }^{4}$ As we can see financial wealth is the driving force of the increasing wealth to income ratio, while housing wealth (net of mortgages) and

\footnotetext{
${ }^{3}$ Domestic capital in the data is the sum of agricultural land, housing, the market value of corporations (equities) and the value of non-financial assets net of liabilities.

${ }^{4}$ Recall that our focus is on the 1980s and 1990s, we will discuss this period choice in more detail later. Data are taken from the online appendix table US.6c.
} 
non-financial assets are fairly constant. ${ }^{5}$

Figure 1. Composition of Private Wealth, 1970-00, \% National Income

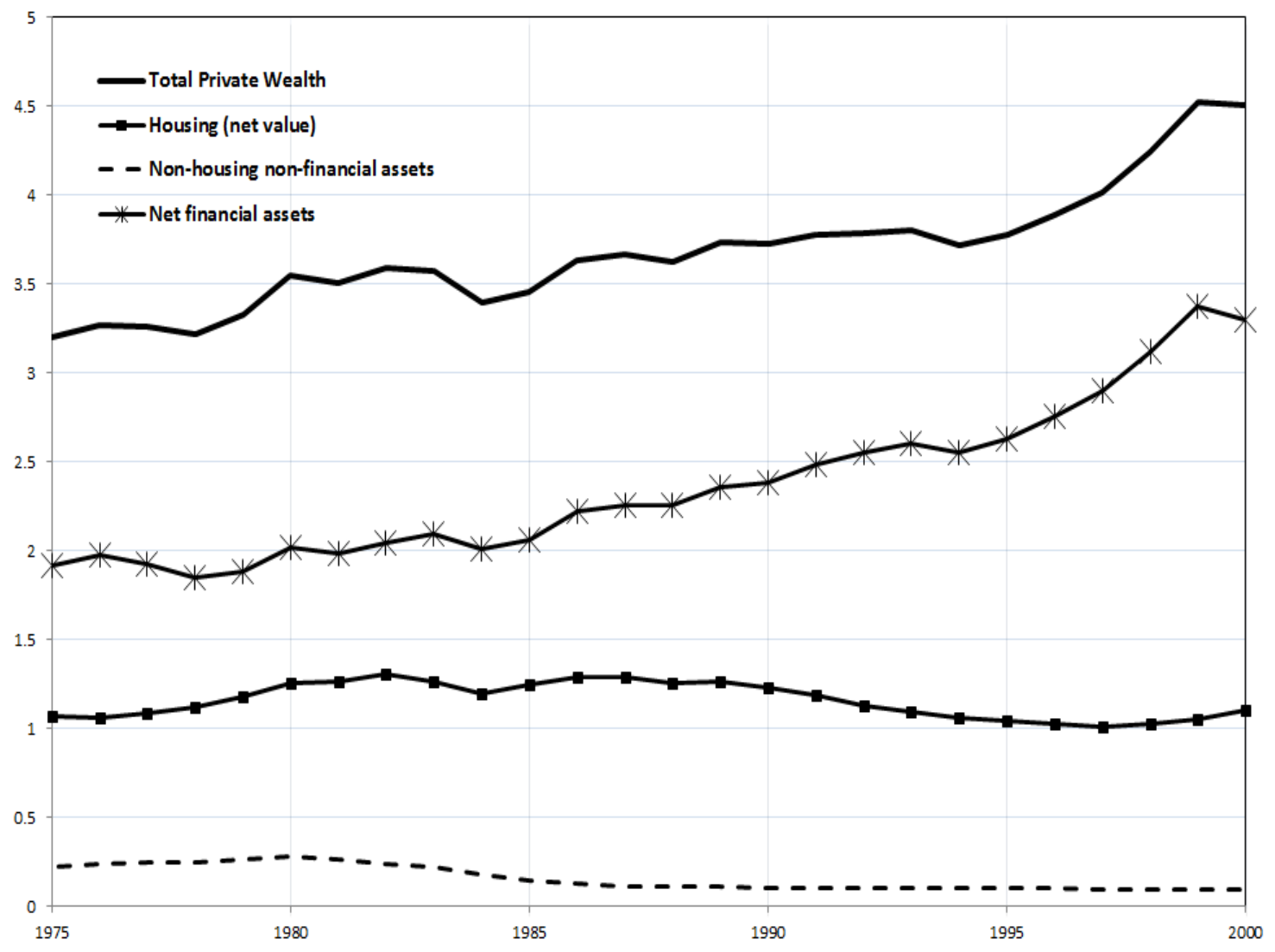

Source: Piketty and Zucman (2014)

About two thirds of financial assets are accounted for by corporate wealth. In Figure 2, we report the two measures of corporate wealth constructed by Piketty and Zucman (2014). ${ }^{6}$ The first measure is the equity value, which is the market value of the firm, and the second is the net worth, which is the "book value" of the firm. The last measure comes from perpetual inventory method-based estimates of tangible assets. The difference between the two measures is the residual corporate wealth, and the ratio between the two measures of corporate wealth is the well-known Tobin's Q.

\footnotetext{
${ }^{5}$ Non financial assets include produced tangible capital, non-produced tangible capital, and intangible capital. Tangible assets is the typical economic measure of capital which includes all tangible fixed assets: buildings and structures, machinery and equipment, cultivated biological resources, and weapon systems, etc. Non-produced tangibles includes natural resources such as land, oil, gas, etc. Intagible assests are R\&D expenditure, intellectual property, etc. See Piketty and Zucman (2014) online data appendix for details.

${ }^{6}$ Piketty and Zucman (2014) online appendix table US.6b.
} 


\section{Figure 2. Corporate Wealth, 1970-00, \% of National Income}

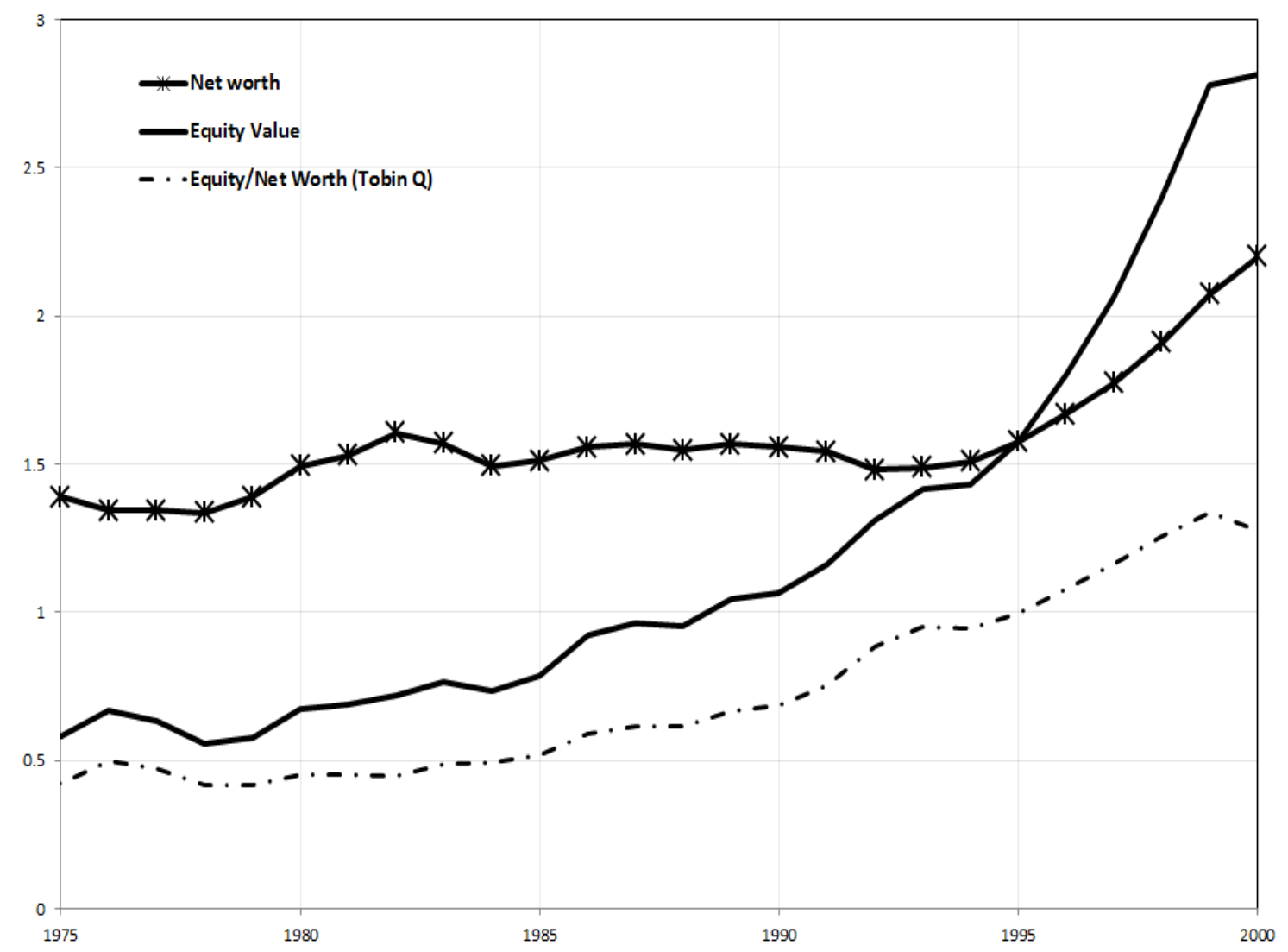

Source: Piketty and Zucman (2014)

Both measure of corporate wealth exhibit a striking increase in the period of interest. The book value rises from $150 \%$ of income in 1980 to $220 \%$ in 2000 , while the equity value from $67 \%$ in 1970 skyrockets to $280 \%$ in 2000 .

International technological competition. During this period of increasing wage polarization and fast growing wealth, the US experiences increasing foreign technological competition. The data show a global convergence pattern in several measures of innovation performance. The US, the undisputed technological leader in the post-World War II period, is progressively challenged by Japan and European countries in the late 1970s and 1980s. Figure 3, shows the stark convergence in patent shares in the US Patent office; in 1977 about two thirds of patents came from American firms, while ten years later only one half of patents had US origin. Most of the convergence takes place in the 1970s and 1980s, while the following years show no major changes, with the shares in 2005 being virtually identical to those in the late 1980s.

This convergence in patenting activity did not happen because of a slowdown in US patenting but it is due to a stark acceleration in foreign patents. The number of foreign patents grew by about 60\% between 1977 and 1988, while US patents did not show any sensible change in 
those years. This increase is mainly driven by Japan, whose share rose from $9 \%$ in 1977 to about $20 \%$ in 1988. Along these lines, Akcigit, Ates, and Impullitti (2014) show that a similar trend can be seen in patent citations, and disaggregating at the level of technology classes, they document a convergence trend in global patenting also at the micro/sectorial level. Together with convergence in innovation output (patents), recent research has also highlighted similar patterns for global innovation inputs. Impullitti (2010) documents a strong convergence in private R\&D spending between the US and a group of fast growing advanced economies in the 1970s and 1980s.

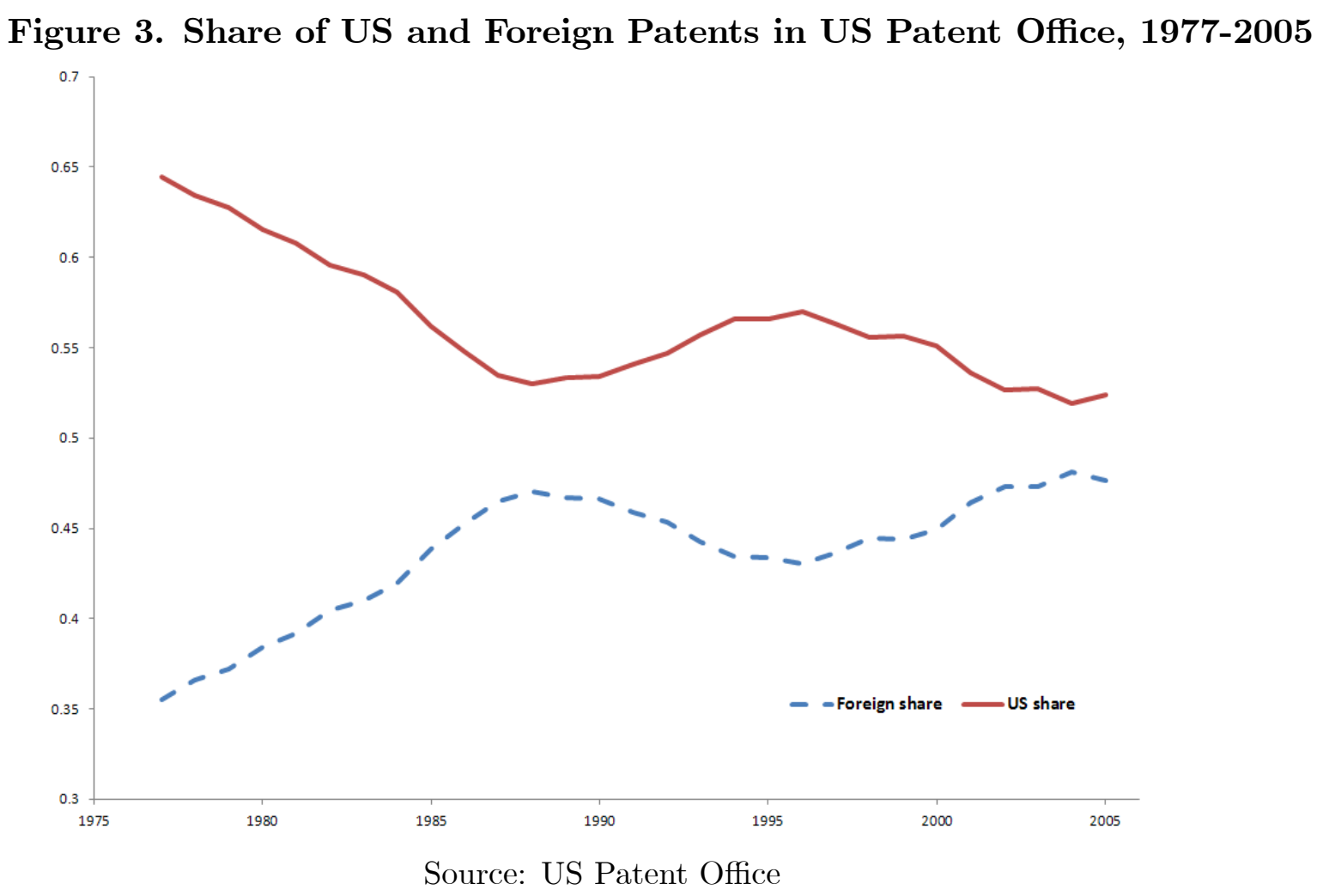

In what follows we build a theory to analyse the effects of foreign technological competition on the wage and occupational structure, and on the dynamics of the wealth to income ratio. We then use the data discussed here to assess the link between foreign competition and our key measures of inequality quantitatively. More precisely, we use the model to replicate the change in patent shares observed in Figure 3, measure the changes in wage polarization and the wealth to income ratio implied by the model and compare them to those in the data shown in Table 1 and 2 and Figures 1 and 2.

\section{The model}

In this section, we set up the main model and derive the steady state equilibrium conditions. 


\subsection{Households}

Consumption. The economy is populated by two regions with the same population and preferences. In both regions, there are heterogeneous households, differing in their ability to acquire working skills $\theta \in[0,1]$. Households have identical preferences for a continuum of consumption goods $\omega \in[0,1]$, and each is endowed with a unit of labour/study time whose supply generates no disutility. Household of type $\theta$ is modelled as dynastic family that maximizes intertemporal utility

$$
U=\int_{0}^{\infty} N(0) e^{-(\rho-n) t} \ln u_{\theta}(t) d t
$$

where population is specified according to $N(t)=N(0) e^{n t}$, with initial population $N(0)$ normalized to 1 and a constant population growth rate $n$. The rate of time preference is $\rho$, with $\rho>n$. The utility per person is given by

$$
u_{\theta}(t) \equiv\left[\int_{0}^{1}\left(\sum_{j=0}^{j^{\max }(\omega, t)} \lambda^{j} d_{\theta}(j, \omega, t)\right)^{\frac{\eta-1}{\eta}} d \omega\right]^{\frac{\eta}{\eta-1}}
$$

where $d_{\theta}(j, \omega, t)$ is the per-member quantity of good $\omega \in[0,1]$ of quality $j \in\{0,1,2, \ldots\}$ purchased by a household of ability $\theta$ at time $t \geq 0$. A new vintage of good $\omega$ yields a quality $\lambda$ times that of the previous vintage, with $\lambda>1$. Different versions of the same good $\omega$ are regarded by consumers as perfect substitutes after adjusting for their quality ratios, and $j^{\max }(\omega, t)$ denotes the maximum quality in which the good $\omega$ is available at time $t$. Parameter $\eta \in[1, \infty)$ is the elasticity of substitution across varieties, which allows for gross substitutability across varieties.

At each point in time households choose the quantity purchased of each good $d_{\theta}(j, \omega, t)$ in order to maximize (2) subject to the per-period expenditure constraint $\int_{0}^{1} d_{\theta}(j, \omega, t) p(j, \omega, t) d \omega=$ $c_{\theta}(t)$, where $c_{\theta}(t)$ is planned time $t$ consumption expenditure. Notice that the household will be purchasing in each line only the product with the lowest price per unit of quality. Hence, household's demand for each product is:

$$
d_{\theta}(j, \omega, t)=c_{\theta}(t) \frac{q(\omega, t) P(t)^{\eta-1}}{p(j, \omega, t)^{\eta}},
$$

where $q(\omega, t)=\lambda^{(\eta-1) j^{\max }(\omega, t)}$ represents the quality of good $\omega$ and $P(t)$ is a general price index, defined as:

$$
P(t)=\left[\int_{0}^{1} q(\omega, t) p\left(j^{\max }(\omega, t), \omega, t\right)^{1-\eta} d \omega\right]^{\frac{1}{1-\eta}} .
$$

Notice that the quality of the demanded version of a variety, $q(\omega, t)$, positively affects its quantity, while negatively affecting the overall price index. Given the optimal allocation of expenditures across different product lines at a given moment $t$ in (3), households choose 
the intertemporal allocation of consumption maximizing (1) with respect to the intertemporal budget constraint $\dot{a}_{\theta}(t)=w_{\theta}(t)+(r(t)-n) a_{\theta}(t)-c_{y}(t)$, where asset market clearing implies that per-capita assets are equal to the sum of firm values $a(t)=\int_{0}^{1} v(\omega, t) d \omega$. This problem yields

$$
\frac{\dot{c_{\theta}}(t)}{c_{\theta}(t)}=r(t)-\rho
$$

the standard Euler equation for consumption.

Supply of skills. Individuals are finitely-lived members of infinitely-lived households, being continuously born at rate $\beta_{n}$ and dying at rate $\delta$, with $\beta_{n}-\delta=n>0 ; V>0$ denotes the exogenous duration of their life ${ }^{7}$. They choose to acquire education and become skilled, if at all, at the beginning of their lives, and the duration of their schooling period, during which the individual cannot work, is set at $T_{H}<V$. We assume agents have heterogeneous innate abilities drawn from a cumulative distribution function $\Gamma(\theta)$.

In country $K=D$ (domestic), $F$ (foreign) an individual with ability $\theta$ decides to acquire education if and only if:

$$
\int_{t}^{t+V} e^{-\int_{t}^{s} r(\tau) d \tau} \theta w_{L}^{K}(s) d s \leq \int_{t+T_{H}}^{t+V} e^{-\int_{t}^{s} r(\tau) d \tau} \max \left(\theta-\gamma_{H}, 0\right) w_{H}^{K}(s) d s,
$$

with $0<\gamma_{H}<1$ defining a threshold ability requirement so that an agent with ability $\theta>\gamma_{H}$ is able to accumulate $\theta-\gamma_{H}$ units of skills after schooling, while a person with ability below $\gamma_{H}$ gains no skills from education. Parameter $\gamma_{H}$ can be interpreted as a fixed cost of education. ${ }^{8}$ We will here focus on steady-state analysis, in which all variables grow at constant rate and $w_{L}, w_{H}$, and $c_{\theta}$ are all constant ${ }^{9}$. From the Euler equation (4) we obtain $r(t)=\rho$ at all dates. Equation (5) yields the cutoff ability level $\theta_{0}^{K}$ above which agents acquire education:

$$
\frac{w_{H}^{K}}{w_{L}^{K}}=\sigma_{1}\left(\frac{\theta_{0}^{K}}{\theta_{0}^{K}-\gamma_{H}}\right)
$$

with $\sigma_{1} \equiv\left[\left(e^{\rho V}-1\right) /\left(e^{\rho\left(V-T_{H}\right)}-1\right)\right]>1$. Notice that, since $0<\gamma_{H}<1$, we have $\partial\left(w_{H}^{K} / w_{L}^{K}\right) / \partial \theta_{0}^{K}<0$ : an increase in the relative skilled wage reduces the ability cutoff to acquire education.

Each unskilled individual can work either in production occupations or as a personal service worker. Personal services allow people to spend less time on house chores, baby-sitting, transportation, and other activities, which would otherwise detract time from other kinds of

\footnotetext{
${ }^{7}$ It is easy to show that the above parameters cannot be chosen independently, but that they must satisfy $\delta=n /\left(e^{n V}-1\right)$ and $\beta=n e^{n V} /\left(e^{n V}-1\right)$ in order for the number of births at time $t$ to match the number of deaths at $t+V$.

${ }^{8}$ This way of modeling the accumulation of skills has been first introduced by Findlay and Kierzkowski (1983), and extended to heterogeneous agents by Dinopoulos and Segerstrom (1999). Unlike these models, we also feature heterogeneous abilities among unskilled workers, which is an important empirical aspect of the labour market.

${ }^{9}$ An analysis of the transitional dynamics could be carried out numerically, along the lines of Cozzi and Impullitti (2010) and Cozzi and Galli (2014).
} 
activities, such as production and innovation occupations. Since in this model individuals do not have a desire for leisure, we can assume that each hour saved thanks to service workers will be used to work more. We will also posit that there is an upper bound, normalized to $1^{10}$, of the extra work made possible by personal services. Moreover, each unit time of personal service provides its employer, who must be a different person, $1-\epsilon$ extra time for work, with $0<\epsilon<1$. This implies that in equilibrium unskilled workers of same or lower ability levels will not demand services, because it would cost $w_{D}^{K}$ to obtain an extra labour time which pays $w_{D}^{K}(1-\epsilon)$.

A high skilled worker of generic ability $\theta$ finds it profitable to buy personal services from an unskilled worker of ability $\theta^{\prime}$, if at the cost of $\theta^{\prime} w_{L}^{K}$ they can obtain an additional wage income $w_{H}^{K}(1-\epsilon) \theta \geq \theta^{\prime} w_{L}^{K}$. The lowest possible $\theta$ at which hiring a personal service is worthwhile in country $K$, denoted $\theta_{H S}^{K}$, and the higher possible $\theta^{\prime}$ supplied by the unskilled, denoted $\theta_{L S}^{K}$, must equalize service cost and employer's economic benefit, that is:

$$
\theta_{L S}^{K} w_{L}^{K}=w_{H}^{K}(1-\epsilon)\left[\theta_{H S}^{K}-\gamma_{H}\right] .
$$

The mass of service workers must be equal to the mass of skilled workers employing them,

$$
\Gamma\left(\theta_{L S}^{K}\right)=1-\Gamma\left(\theta_{H S}^{K}\right) .
$$

Plugging the eq. (8) into eq. (7) and solving for $\theta_{L S}^{K}$ gives

$$
\theta_{L S}^{K}\left(\theta_{H S}^{K}\right) \equiv \Gamma^{-1}\left(1-\Gamma\left(\theta_{H S}^{K}\right)\right)=\frac{w_{H}^{K}}{w_{L}^{K}}(1-\epsilon)\left[\theta_{H S}^{K}-\gamma_{H}\right]
$$

which since $\Gamma^{-1}($.$) is monotonically increasing, gives \theta_{H S}^{K}$ as a decreasing function of the relative skilled wage, and therefore $\theta_{L S}^{K}$ as an increasing function of the relative skilled wage. Intuitively, a higher relative remuneration of skilled occupations increases the demand for service occupations. Hence, invoking (6), we can write:

$$
\frac{d \theta_{H S}^{K}}{d \theta_{0}^{K}}>0>\frac{d \theta_{L S}^{K}}{d \theta_{0}^{K}} .
$$

The fraction of the population opting out of education determines the per-capita supply of unskilled labour $L^{K} \equiv \widetilde{\theta}_{L}^{K} \Gamma\left(\theta_{0}^{K}\right)$, where

$$
\widetilde{\theta}_{L}^{K}=\left[\int_{0}^{\theta_{0}^{K}} \theta \frac{d \Gamma(\theta)}{\Gamma\left(\theta_{0}^{K}\right)}\right]
$$

is the average ability of a generic unskilled worker. Notice that $d L^{K} / d \theta_{0}^{K}=\theta_{0}^{K}>0$, the supply of unskilled workers is increasing in $\theta_{0}^{K}$. Intuitively, higher relative skilled wage reduces the cutoff ability to acquire education $\theta_{0}^{K}$, thereby reducing the share of unskilled workers.

\footnotetext{
${ }^{10}$ There is no restriction in this normalisation: we can easily generalise this upper bound.
} 
A fraction $1-\Gamma\left(\theta_{0}^{K}\right)$ of the population decides to attain education and the skilled workforce is represented by the subset of these agents that as of date $t$ have completed their schooling period, that is individuals born between $t-V$ and $t-T_{r}$. The per-capita supply of skilled labour in efficiency units at time $t$ is then

$$
H^{K}=\tilde{\theta}_{H}^{K}\left[1-\Gamma\left(\theta_{0}^{K}\right)\right] \int_{t-V}^{t-T r} \beta_{n} N(0) e^{n s} d s=\widetilde{\theta}_{H}^{K}\left[1-\Gamma\left(\theta_{0}^{K}\right)\right] \phi,
$$

with $0<\phi \equiv\left(e^{n\left(V-T_{r}\right)}-1\right) /\left(e^{n V}-1\right)<1$ and

$$
\begin{aligned}
\tilde{\theta}_{H}^{K} & =\left[\int_{\theta_{0}^{K}(t)}^{1}\left(\theta-\gamma_{H}\right) \frac{d \Gamma(\theta)}{1-\Gamma\left(\theta_{0}^{K}(t)\right)}\right]= \\
& =(2-\epsilon) \int_{\theta_{H S}^{K}}^{1}\left(\theta-\gamma_{H}\right) \frac{d \Gamma(\theta)}{1-\Gamma\left(\theta_{0}^{K}\right)}+\int_{\theta_{0}^{K}}^{\theta_{H S}^{K}}\left(\theta-\gamma_{H}\right) \frac{d \Gamma(\theta)}{1-\Gamma\left(\theta_{0}^{K}\right)}
\end{aligned}
$$

is the average ability of educated workers. Using (13) and (10) we derive

$$
d H^{K} / d \theta_{0}^{K}=-\left[(1-\epsilon) \frac{d \theta_{H S}^{K}}{d \theta_{0}^{K}}+1\right]\left(\theta_{0}^{K}-\gamma_{H}\right) \Gamma^{\prime}\left(\theta_{0}^{K}\right) \phi<0,
$$

hence the supply of skills is decreasing in $\theta_{0}^{K}$.

\subsection{Production}

In each country, firms can hire unskilled workers to produce consumption good $\omega \in[0,1]$ under a constant returns to scale technology with one worker producing one unit of product. The unskilled wage rate is $w_{L}^{K}$ and we set $w_{L}^{F}=1$, so that the unskilled foreign wage is the numeraire of this economy. Assuming instantaneous price competition, Bertrand equilibrium implies that in each industry only the product with the highest quality is produced. Quality leaders in each sector are challenged by followers that employ skilled workers to discover the next topquality product. In this model, as in the quality ladder growth literature, a patent expires as soon as the next top-quality product is invented ${ }^{11}$. Successful innovation yields global market leadership, which is protected by a perfectly enforceable patent law.

We assume that the technologies to produce goods one quality ladder below the top are obsolete and diffuse freely. This assumption allows foreign successful innovators to become global market leaders. ${ }^{12}$ We allow for international trade in goods, but we do not consider multinational companies in this model. In addition, while allowing for perfect patent protection, we

\footnotetext{
${ }^{11}$ Which guarantees that within a country the firm profts are invariant regardless of the patent holder of the top-quality product - i.e. even if the industry leader owns (by purchase or innovation) the patent on the new product.

${ }^{12}$ Without this assumption if a leader experiences successive innovations, followers will be pushed out of the market permanently. The assumption of immediate diffusion of the old production technology is discussed in Glass (1997) and widely used both in North-North models of trade and growth (e.g. Dinopoulos and Segerstrom, 1999), and in North-South models (Glass, 1997, Glass and Saggi, 1998).
} 
rule out an international market for patent royalties ${ }^{13}$. Therefore, in our model, only domestic firms can produce and export the goods patented in the country. Finally, we do not consider international trade in assets.

As will become clearer in the next sections, a consequence of our assumption of technological gap between the two countries - i.e. with country $D$ more efficient in innovation than country $F$ - country $D$ gains global market leadership in a wider range of sectors, which drives up the demand for its manufacturing labour. For this reason, in all our equilibria the unskilled wage in country $D$ will be higher than that of country $F$, that is $w_{L}^{D}>w_{L}^{F}=1$.

Since both domestic and foreign followers operate with the same technology, and foreign unskilled labour is cheaper, as we will prove, domestic followers do not represent an effective competitive threat. Moreover, we assume that the quality jump $\lambda$ is not high enough that each top-quality producer firm can maximize profits unconstrained in both markets ${ }^{14}$. Thus the price $p^{K}\left(j^{\max }(\omega, t), \omega, t\right)$ of a top quality good in each sector $\omega$ at time $t$ is

$$
p^{K}\left(j^{\max }(\omega, t), \omega, t\right)=\lambda w_{L}^{F}(t)=\lambda>1
$$

in any country $K=D, F$. Notice that this implies that $w_{L}^{D} \leq \lambda w_{L}^{F}$, because otherwise country $D$ firms would lose all markets and unskilled jobs ${ }^{15}$. This "narrow gap" case (Grossman and Helpman, 1991) allows for equilibrium product-cycle trade (Vernon, 1966) with global market leadership shifting from domestic to foreign firms as the latter innovate and viceversa. Although the foreign region has a cost advantage in production, equilibrium guarantees that the wage gap is not so large that a foreign follower can price a domestic leader out of the market without innovating.

From the static consumer demand (3), we can conclude that the demand for each product $\omega$ is:

$$
N(t)\left(c^{D}(t)+c^{F}(t)\right) \frac{q(\omega, t) P(t)^{\eta-1}}{p(j, \omega, t)^{\eta}}=d(\omega, t),
$$

where $c^{K}(t)=\int_{0}^{1} c_{\theta}^{K}(t) d \theta$ for $K=D, F$ are average per-capita expenditures at time $t$. Notice that under the pricing condition (14) the price index becomes,

$$
\begin{aligned}
P(t)^{\eta-1} & =(\lambda)^{\eta-1} / \int_{0}^{1} q(\omega, t) d \omega= \\
& =\lambda^{\eta-1} / Q(t)
\end{aligned}
$$

\footnotetext{
${ }^{13}$ Otherwise a domestic firm could license a top quality good patent to a foreign firm, extracting all profits. Realistically speaking, in the period we consider in the paper (1979-1995) intellectual property royalties from foreign unaffiliated firms did not play any major role for the United States: receipts never exceeded 7.5 billion US\$ (Bureau of Economic Analysis, 2007, data table A6.3), hence we can safely ignore this possibility.

${ }^{14}$ Cases in which this does not hold can be easily handled, with no qualitative change in the results. We have decided not to spell them out explicitly in order for the exposition to be less cumbersome. Hence in all our calibrations constraint $\eta /(1-\eta)>\lambda$ must hold.

${ }^{15}$ This includes those in the service sector, because innovation would stop - due to lack of expected profits in manufacturing, and skilled workers would lose their jobs as well.
} 
where $Q(t)=\int_{0}^{1} q(\omega, t) d \omega$ is the average quality in the economy. Therefore, using (15) and dropping time indexes for notational simplicity, we can write:

$$
d(\omega)=\frac{N\left(c^{D}+c^{F}\right) q(\omega)}{\lambda Q}, \text { for } \omega \in[0,1] .
$$

Since supply and demand of goods are equal in equilibrium, the stream of monopoly profits accruing to domestic quality leaders is

$$
\begin{aligned}
\pi_{n}^{D}(\omega) & =d(\omega)\left(\lambda w_{L}^{F}-w_{L}^{D}\right)= \\
& =\frac{N\left(c^{D}+c^{F}\right) q(\omega)}{\lambda Q}\left(\lambda-w_{L}^{D}\right),
\end{aligned}
$$

and the profits of the foreign leaders are

$$
\pi^{F}(\omega)=\frac{N\left(c^{D}+c^{F}\right) q(\omega)(\lambda-1)}{\lambda Q} .
$$

Notice that $\pi^{F}(\omega)$ is lower than the unconstrained monopoly profit $N\left(c^{D}+c^{F}\right) q(\omega) / \eta Q$, because the quality jump size is not enough to allow the firm to ignore the possibility of the competitive fringe re-entering the market at monopolistic prices. This induces the new market leader to limit-price the competitive fringe and sell their goods at a price equal to the quality-adjusted unit cost of the potential entrants in country $F$.

\subsection{Global innovation races and the value of a firm}

In each industry, firms employ skilled workers to produce a probability intensity of inventing the next top-quality version of their products. The arrival rate of innovation in industry $\omega$ at time $t$ is $I(\omega, t)$, which is the sum of the Poisson arrival rate of innovation produced by all firms targeting product $\omega$. The innovation technology available to a firm $i$ in region $K$ for innovation in sector $\omega$ is

$$
I_{i}^{K}(\omega, t)=\frac{A^{K} h_{i}^{K}(\omega, t)\left(\frac{H^{K}(\omega, t)}{X(\omega, t)}\right)^{-\alpha}}{X(\omega, t)},
$$

where $X(\omega, t)>0$ measures the degree of complexity of innovation, $\alpha$ is a positive congestion parameter, and $H^{K}(\omega, t)=\sum_{i} h_{i}^{K}(\omega, t)$ and $I^{K}(\omega, t)=\sum_{i} I_{i}^{K}(\omega, t)$ are the total skilled labour and the total innovation rates in sector $\omega$ and country $K$ respectively. This technology implies that each firm's instantaneous probability of success is a decreasing function of the total domestic labour resources devoted to innovation in an industry. A possible interpretation of this property is that when firms increase innovation inputs in a sector, the probability of duplicative innovation effort also increases, thereby reducing the probability that any single firm will discover the next vintage of goods. Therefore, the sector-specific negative externality in innovation technology produces decreasing returns to innovation at the industry level. Moreover, 
(18) implies that this negative externality is also region-specific; ${ }^{16}$ this feature can be motivated by the presence of fixed costs, such as lab equipment, by institutional differences, and by the presence of a workforce with heterogeneous ability in research. ${ }^{17}$

Notice that eq. (18) implies:

$$
I^{K}(\omega, t)=A^{K}\left(\frac{H^{K}(\omega, t)}{X(\omega, t)}\right)^{1-\alpha} .
$$

The complexity index $X(\omega, t)$ is introduced to avoid the counterfactual prediction of the first generation innovation-driven growth models that the size of a region affects its steady-state growth (Jones, 1995). Following Li (2003), we eliminate the strong scale effect by assuming

$$
X(\omega, t)=\frac{q(\omega, t)}{Q(t)^{\phi_{1}}}
$$

with $0<\phi_{1}<1$. Therefore, the more advanced the good relative to the average quality the more difficult a further innovation. Moreover, even for an average quality good (i.e. if there exists an $\omega$ such that $q(\omega, t)=Q(t))$, the higher the average quality itself the more difficult innovation (in this case $X(\omega, t)=Q_{t}^{1-\phi_{1}}$ ), which incorporates Jones' (1995), Kortum's (1997), and Segerstrom's (1998) increasing complexity argument to rule out the strong scale effect. ${ }^{18}$

Notice that (20) implies that, log-differentiating the difficulty index between quality jumps in the sector, its evolution obeys

$$
\frac{\dot{X}(\omega, t)}{X(\omega, t)}=-\phi_{1} \frac{\dot{Q}(t)}{Q(t)} .
$$

Each innovating firm chooses the labour resources devoted to innovation $h_{i}^{K}$ in order to maximize its expected discounted profits. Free entry into innovation races drives profits to zero, yielding

$$
v^{K}(\omega, t)\left(\frac{I^{K}(\omega, t)}{A^{K}}\right)^{\frac{-\alpha}{1-\alpha}} \frac{A^{K}}{X(\omega, t)}=w_{H}^{K}(t),
$$

where $v^{K}(\omega, t)$ is the value of a firm in sector $\omega$ and country $K$, and we used (19) to substitute for $H^{K}(\omega, t)$. This condition states that the cost of one unit of skilled labour employed in

\footnotetext{
${ }^{16}$ There is strong empirical evidence on the nonlinearity of the relationship between innovative activity of a country (measured using patent data) and its R\&D investment. Working with a large sample of US firm-level data, Hall et al. (1986) find an elasticity of patents to R\&D of 0.5. The evidence surveyed in Kortum (1993) suggests point estimates for the patent/R\&D elasticity in the range $0.1-0.6$. More recently, Blundell et al. (2002) find a long-run elasticity of 0.5 .

${ }^{17}$ Eaton and Kortum (1999) adopt a similar technology in their multi-country version of the quality ladder growth model. They suggest a microfundation for decreasing returns in innovation at the country level based on heterogeneous ability workers. As investment in innovation increases in a country, workers of lower ability will be used and productivity will decline. This microfundation applies to this model as well.

${ }^{18} \mathrm{An}$ equally valid solution to the scale effects problem is based on the assumption that aggregate innovation becomes more difficult over time as it is spread over more varieties (see e.g. Dinopoulos and Thompson, 1998, Peretto, 1998, Howitt, 1999). Given that our focus is on inequality and not on growth, we adopt the increasing complexity specification of the difficulty index.
} 
innovation $w_{H}^{K}$ must be equal to its benefits, represented by the marginal probability intensity $A^{K}\left(L^{K}(\omega, t) / X(\omega, t)\right)^{-\alpha} / X(\omega, t)$ times the prize for a successful innovation $v^{K}(\omega, t)$.

Notice that, despite the leaders and followers having the same production and innovation technology, the free entry condition implies that we can compute the equilibrium focusing only on the followers' innovation. If incumbents would innovate, they would replace themselves as market leaders, hence losing the current value of their firm. This implies that in equilibrium only followers innovate. ${ }^{19}$

Efficient financial markets channel savings into innovative firms that issue a security paying the new monopoly stock market value if they win the race and zero otherwise. Since there is a continuum of industries, and simultaneous and independent innovation races, consumers can perfectly diversify away risk: the expected rate of return of a stock issued by a firm is equal to the riskless rate of return $r(t)$. It is easy to show that this leads to the following stock market value of a firm:

$$
v^{K}(\omega, t)=\frac{\pi^{K}(\omega, t)}{r(t)+I(\omega, t)-\dot{v}^{K}(\omega, t) / v^{K}(\omega, t)},
$$

where $I(\omega, t)$ denotes the worldwide Poisson arrival rate of an innovation that will destroy the monopolist's profits in industry $\omega$. This is the Schumpeterian rate of creative destruction, which implies that the expected value of a patent is decreasing in the total innovation of the industry. Substituting for the value of the firm from (23) into (22) and using (18) to express the amount of skilled workers in terms of the innovation rate we obtain the following conditions

$\frac{\pi^{K}(\omega, t)}{r(t)+I(\omega, t)-\dot{v}^{K}(\omega, t) / v^{K}(\omega, t)}\left(\frac{I^{K}(\omega, t)}{A^{K}}\right)^{\frac{-\alpha}{1-\alpha}} \frac{A^{K}}{X(\omega, t)}=w_{H}^{K}(t)$, for $\omega \in[0,1]$ and $K=D, F$

This condition, together with the Euler equation, summarizes the utility maximizing household choice of consumption, savings, and education, and the profit maximizing choice of production and innovation. Innovation arrival rates determine the evolution of the average quality of goods in the economy $Q_{t}$.

In all industries, firms from both regions compete in innovation. This leads to the following composition of worldwide investment in innovation:

$$
I(\omega, t)=I^{D}(\omega, t)+I^{F}(\omega, t),
$$

where $I^{D}(\omega, t)$ is domestic innovation and $I^{F}(\omega, t)$ is foreign innovation.

Assumption 1 (Technology Gap). $A^{D}>A^{F}$.

We introduce a gap between the two countries in terms of the innovation technology parameter $A$. Since goods $\omega \in[0,1]$ are symmetric (same technologies, both in production and innovation, and enter symmetrically the utility function), the only source of structural asymmetry between the two countries is the difference between their innovation productivities.

\footnotetext{
${ }^{19}$ This is the celebrated Arrow effect, introduced by Aghion and Howitt (1992) into Schumpeterian growth theory. See Cozzi (2007) for a general interpretation.
} 
Since there is no sectorial heterogeneity in this economy, we can write, $I^{D}(\omega, t)=I^{D}(t)$ and $I^{F}(\omega, t)=I^{F}(t)$ for all $\omega$. In a steady state, the per-industry probabilities of innovation per unit of time will be constant over time, which allows us to drop time indexes and write $I^{D}$ and $I^{F}$. Differentiating $Q$ with respect to time, it is straightforward to prove that:

$$
\begin{aligned}
\dot{Q} & =\left(I^{F} \int_{0}^{1}\left(\lambda^{(j(\omega)+1)(\eta-1)}-\lambda^{j(\omega)(\eta-1)}\right) d \omega+I^{D} \int_{0}^{1}\left(\lambda^{(j(\omega)+1)(\eta-1)}-\lambda^{j(\omega)(\eta-1)}\right) d \omega\right) \\
g & =\frac{\dot{Q}}{Q}=\left(\lambda^{\eta-1}-1\right)\left(I^{D}+I^{F}\right) .
\end{aligned}
$$

Hence, the growth rate of aggregate quality is proportional to the global arrival rate of innovation.

\subsection{Labour markets}

The production technology specified above implies that the demand for unskilled workers is equal to the total production of goods in each national economy plus the total demand for personal services. The unskilled labour market clearing condition is

$$
\left[\Gamma\left(\theta_{0}^{K}\right)-\left(1-\Gamma\left(\theta_{H S}^{K}\right)\right)\right] \widetilde{\theta}_{M}^{K}=\frac{\left(c^{D}+c^{F}\right)}{\lambda} q^{K}
$$

where

$$
\widetilde{\theta}_{M}^{K}=\left[\int_{\theta_{L S}^{K}}^{\theta_{0}^{K}} \theta^{K} \frac{d \Gamma(\theta)}{\Gamma\left(\theta_{0}^{K}\right)-\Gamma\left(\theta_{L S}^{K}\right)}\right]
$$

is the average ability of unskilled workers employed in production. The left-hand side is the supply of unskilled workers in manufacturing in efficiency units. The right-hand side is the demand for unskilled workers. We define $q^{K}=Q^{K} / Q$, as the share of sectors with country $K^{\prime} s$ leadership, where $Q^{K}=\int_{B^{K}} q(\omega) d \omega$ is the average quality of the sectors in which country $K$ has global leadership ( $B^{K}$ is the measure of these sectors), and $q^{D}+q^{F}=1$ by construction. ${ }^{20}$

The market clearing condition for skilled workers is

$$
\begin{aligned}
\widetilde{\theta}_{H}^{K}\left(1-\Gamma\left(\theta_{0}^{K}\right) \phi\right. & =\left(\frac{I^{K}}{A^{K}}\right)^{1 /(1-\alpha)} \int_{0}^{1} \frac{X(\omega)}{N} d \omega= \\
& =\left(\frac{I^{K}}{A^{K}}\right)^{1 /(1-\alpha)} x \text { for } K=D, F
\end{aligned}
$$

where we define $x=Q^{1-\phi} / N=\int_{0}^{1} X(\omega) d \omega / N$, which is the aggregate difficulty index of innovation normalized by population. The left-hand side is the domestic supply of skilled labour (per capita) from (12), and the right-hand side is the domestic demand for skilled workers obtained after integrating equations (18) and (20).

\footnotetext{
${ }^{20}$ At any point in time $B^{D} \cup B^{F}=[0,1]$, that is each sector is either monopolized by a country $D$ firm or by a country $F$ firm. The measure of such sets is $q^{D}$, respectively $q^{F}$, with $q^{D}+q^{F}=1$. Notice that each $B^{K}$ changes over time as firms of different countries alternate their market leadership, but in the steady state its measure is constant. Moreover, $\dot{q}^{D}=q^{D} I^{D}-\left(1-q^{D}\right) I^{F}$, and $\dot{q}^{D}=0$ if and only if $q^{D}=\frac{I^{D}}{I^{D}+I^{F}}$.
} 
Wage Inequality. Since our main aim is to analyse the link between the technology gap and wage inequality, we need to specify the measures of inequality we want to focus on. The education choice and demand for service sector workers partition the worker/ability space as follows. Skilled workers are those whose abilities lie in $\left[\theta_{H S}^{K}, 1\right]$, who hire unskilled workers to perform personal services and therefore have extra time and income, and those, with ability in $\left[\theta_{0}^{K}, \theta_{H S}^{K}\right)$, who do not hire unskilled workers for performing personal services. The unskilled workers with ability in $\left(\theta_{L S}^{K}, \theta_{0}^{K}\right]$ work in the manufacturing sector, while those in $\left[0, \theta_{L S}^{K}\right]$ work in services. Hence, the average wage of skilled workers is the skilled wage per unit of skills $w_{H}^{D}$ times the average skill level of educated workers:

$$
\tilde{w}_{H}^{D}=w_{H}^{D} \widetilde{\theta}_{H}^{D}=\frac{w_{H}^{D}}{1-\Gamma\left(\theta_{0}^{D}\right)}\left[(2-\epsilon) \int_{\theta_{H S}^{D}}^{1}\left(\theta-\gamma_{H}\right) d \Gamma(\theta)+\int_{\theta_{0}^{D}}^{\theta_{H S}^{D}}\left(\theta-\gamma_{H}\right) d \Gamma(\theta)\right] .
$$

Notice that the skilled workers with abilities higher than $\theta_{H S}^{D}$ hire service workers, thus earning the extra $1-\epsilon$ working time. Similarly, the average wage of the unskilled workers employed in production is

$$
\tilde{w}_{L}^{D}=w_{L}^{D} \widetilde{\theta}_{M}^{D}=w_{L}^{D} \int_{\theta_{L S}^{D}}^{\theta_{0}^{D}} \theta \frac{d \Gamma(\theta)}{\Gamma\left(\theta_{0}^{D}\right)-\Gamma\left(\theta_{L S}^{D}\right)}
$$

where $\widetilde{\theta}_{M}^{D}$ represents the average ability of these workers. Finally, the average wage of the service sector workers is

$$
\tilde{w}_{S}^{D}=w_{L}^{D} \widetilde{\theta}_{S}^{D}=w_{L}^{D} \int_{0}^{\theta_{L S}^{D}} \theta \frac{d \Gamma(\theta)}{\Gamma\left(\theta_{0}^{D}\right)-\Gamma\left(\theta_{L S}^{D}\right)} .
$$

We will mainly focus on two wage gaps: the skilled/unskilled (production) workers gap and the unskilled (production)/service workers gap:

$$
\omega_{H}=\frac{\tilde{w}_{H}^{D}}{\tilde{w}_{L}^{D}} \text { and } \omega_{S}=\frac{\tilde{w}_{S}^{D}}{\tilde{w}_{L}^{D}},
$$

both depending on the relative wage and on the relative average ability of workers.

\section{$4 \quad$ Steady-State Equilibrium}

A balanced growth path for this economy is an equilibrium in which per-capita consumption $c^{K}$, innovation $I^{K}$, the share of industries with a domestic leader $q^{D}$, wages $w_{H}^{K}$ and $w_{L}^{K}$, and the ability cutoffs $\theta_{H S}^{K}$ and $\theta_{0}^{K}$ are constant, while the average quality of goods $Q$ grows at a constant rate. Since wages and sectorial innovation probabilities are constant in steady state, the free entry condition (22) and (21) imply that $\dot{v}^{K}(\omega) / v^{K}(\omega)=\dot{X}(\omega) / X(\omega)=-\phi_{1} \dot{Q} / Q$, for $K=D, F$ and for all $\omega \in[0,1]$. Since also skill thresholds $\theta_{0}^{D}$ and $\theta_{0}^{F}$ are constant, from (29) also $Q^{1-\phi_{1}} / / N$ has to be constant, which implies that $\dot{Q} / Q=n /\left(1-\phi_{1}\right)$ and therefore $\dot{X}(\omega) / X(\omega)=n \phi_{1} /\left(1-\phi_{1}\right)$. As a consequence, (26) implies that 


$$
I^{D}+I^{F}=\frac{n}{\left(1-\phi_{1}\right)\left(\lambda^{\eta-1}-1\right)}
$$

Equation (33) dictates a long-term restriction on innovation rates based on the relative quality index and the sector sizes, thereby generalizing the "semi-endogenous growth" restrictions highlighted by Jones (1995), Kortum (1997) and Segerstrom (1998). Quite interestingly, (33) shows that our version of increasing complexity allows some degree of endogeneity in the composition of innovation rates across sectors and countries.

Per-capita expenditure is constant in steady state, then the Euler equation (4) yields $r=\rho$. In steady state, the free entry condition in innovation (24) takes the following general form:

$$
\begin{aligned}
& \frac{\left(c^{D}+c^{F}\right)\left(\lambda-w_{L}^{D}\right)}{\left(\rho+I^{D}+I^{F}+\frac{n \phi_{1}}{1-\phi_{1}}\right) \lambda} A^{D}\left(\frac{1}{x}\right)\left(\frac{I^{D}}{A^{D}}\right)^{\frac{-\alpha}{1-\alpha}}=w_{H}^{D}, \\
& \frac{\left(c^{D}+c^{F}\right)(\lambda-1)}{\left(\rho+I^{D}+I^{F}+\frac{n \phi_{1}}{1-\phi_{1}}\right) \lambda} A^{F}\left(\frac{1}{x}\right)\left(\frac{I^{F}}{A^{F}}\right)^{\frac{-\alpha}{1-\alpha}}=w_{H}^{F},
\end{aligned}
$$

where we have used (24) and the expressions for profits specified above.

Considering $B^{K}$, the subset of sectors in which country $K$ has market leadership, the average quality of goods with domestic leadership evolves as follows

$$
\begin{aligned}
\dot{Q}^{D} & =\left(\int_{B^{F}} \lambda^{(j+1)(\eta-1)} d \omega+\int_{B^{D}}\left(\lambda^{(j+1)(\eta-1)}-\lambda^{j(\eta-1)}\right) d \omega\right) I^{D}-\int_{B^{D}} \lambda^{(j+1)(\eta-1)} I^{F} d \omega \\
& =\lambda Q^{F} I^{D}+(\lambda-1) Q^{D} I^{D}-Q^{D} I^{F}
\end{aligned}
$$

while the average quality of industries with foreign leadership follows

$$
\begin{aligned}
\dot{Q}^{F} & =\left(\int_{B^{D}} \lambda^{(j+1)(\eta-1)} d \omega+\int_{B^{F}}\left(\lambda^{(j+1)(\eta-1)}-\lambda^{j(\eta-1)}\right) d \omega\right) I^{F}-\int_{B^{F}} \lambda^{(j+1)(\eta-1)} I^{D} d \omega \\
& =\lambda Q^{D} I^{F}+(\lambda-1) Q^{F} I^{F}-Q^{F} I^{D} .
\end{aligned}
$$

In equilibrium $\dot{Q}^{D} / Q^{D}=\dot{Q}^{F} / Q^{F}=\dot{Q} / Q$, which allows us to obtain ${ }^{21}$.

$$
q^{K}=\frac{Q^{K}}{Q}=\frac{I^{K}}{I^{D}+I^{F}} .
$$

To close the model we need to specify the national budget constraints. Consumption in each country equates national income, which is the value of the labour income (wages of unskilled and skilled workers) plus firm profits, while saving is equal to total innovation expenditure:

\footnotetext{
${ }^{21}$ Using the definitions $Q=Q^{D}+Q^{F}$ and $q^{K}=Q^{K} / Q$ we can write $\dot{Q}^{D} / Q^{D}=\dot{Q}^{F} / Q^{F}$ as

$$
\lambda \frac{1-q^{D}}{q^{D}} I^{D}+(\lambda-1) I^{D}-I^{F}=\lambda \frac{q^{D}}{1-q^{D}} I^{F}+(\lambda-1) I^{F}-I^{D}
$$
}

which leads to $I^{D} / I^{F}=q^{D} /\left(1-q^{D}\right)$. Rearranging with obtain (36). 


$$
\begin{aligned}
& c^{D}+w_{H}^{D} H^{D}=Y^{D}=\left[\frac{c^{D}+c^{F}}{\lambda} w_{L}^{D}+\frac{c^{D}+c^{F}}{\lambda}\left(\lambda-w_{L}^{D}\right)\right] q^{D}+w_{H}^{D} H^{D}, \\
& c^{F}+w_{H}^{F} H^{F}=Y^{S}=\left[\frac{c^{D}+c^{F}}{\lambda}+\frac{\left(c^{D}+c^{F}\right)}{\lambda}(\lambda-1)\right]\left(1-q^{D}\right)+w_{H}^{F} H^{F},
\end{aligned}
$$

where innovation spending appears both as an expenditure and as income (of the skilled workers). Moreover, to avoid double counting, we net out the wage of the personal service workers, because they are paid by their employers (the skilled workers) in order to earn additional skilled wages. Simplifying the expressions above we can write national income as,

$$
\begin{aligned}
Y^{D} & =\left(c^{D}+c^{F}\right) q^{D}+w_{H}^{D} H^{D}, \\
Y^{S} & =\left(c^{D}+c^{F}\right)\left(1-q^{D}\right)+w_{H}^{F} H^{F},
\end{aligned}
$$

Notice that equations (39) and (40) allow us to obtain expressions for national saving,

$$
\begin{aligned}
& S^{D}=Y^{D}-c^{D}=c^{F} q^{D}-c^{D} q^{F}+w_{H}^{D} H^{D}=w_{H}^{D} H^{D}, \\
& S^{F}=Y^{F}-c^{F}=c^{D} q^{F}-c^{F} q^{D}+w_{H}^{F} H^{F}=w_{H}^{F} H^{F},
\end{aligned}
$$

where we have used the conditions for balanced trade, i.e. country $D$ 's trade balance $c^{F} q^{D}-$ $c^{D} q^{F}$ is zero in the steady state equilibrium. Moreover, equations (37) and (38) are not independent, and they lead to

$$
\frac{c^{D}}{c^{F}}=\frac{q^{D}}{1-q^{D}} .
$$

The steady state equilibrium system is characterized by 13 unknowns $c^{D}, c^{F}, I^{D}, I^{F}, w_{L}^{D}$, $w_{H}^{D}, w_{H}^{F}, \theta_{0}^{D}, \theta_{0}^{F}, \theta_{H S}^{D}, \theta_{H S}^{F}, q^{D}, x$, and 13 equations (6), (9), (27), (29), (33), (34), (35),(36), and (43). Below we analyse its key properties.

\section{Analytical Results}

The goal of this section is to prove some key equilibrium properties of the model. All proofs of propositions can be found in the Appendix. We start with the following:

Proposition 1 In the steady state equilibrium, which always exists and is unique, country $D$ has leadership in a larger share of sectors $\left(q^{D}>q^{F}\right)$ and higher unskilled wages $\left(w_{L}^{D}>1\right)$ than country F.

The higher productivity of innovation, $A^{D}>A^{F}$, renders the domestic country more innovative $\left(I^{D}>I^{F}\right)$, and its firms obtain market leadership in a larger range of sectors $\left(q^{D}>q^{F}\right)$, which sustains a high demand for production workers and guarantees them higher wages than in the rest of the world $\left(w_{L}^{D}>1\right)$.

The next proposition derives some comparative statics results with respect to a technological catch up by country $F$, modelled as an increases in $A^{F}$ given $A^{D}$. 
Proposition 2 A reduction in the innovation technology gap $A^{D} / A^{F}$ produces the following effects on country D:

$i$. The unskilled wage $w_{L}^{D}$ decreases, the relative skilled wage $w_{H}^{D} / w_{L}^{D}$ increases along with the fraction of the population acquiring education (lower $\theta_{0}^{D}$ ).

ii. The fraction of sectors monopolized by its firms $q^{D}$ decreases.

iii. The fraction of the labour force employed in personal services $\theta_{L S}^{D}$ increases and the fraction of labour force employed in production decreases.

The positive effect of foreign technological competition on the relative skilled wage $w_{H}^{D} / w_{L}^{D}$ works through two different channels: the international business-stealing channel and the global competition channel.

International business stealing. An increase in relative innovation efficiency in the foreign country increases relative innovation intensity $I^{F} / I^{D}$, hence reducing the share of sectors with domestic leadership $q^{D}=I^{D} /\left(I^{D}+I^{F}\right)$. This is the business-stealing effect, typical of Schumpeterian models, in an open economy environment with two innovating asymmetric countries: as foreign innovation technology improves, foreign firms obtain global leadership in more sectors; as a consequence, production shifts away from the home market, thereby leading to lower labour demand and lower wages for unskilled production workers.

Global competition effect. The relative skilled wage does not increase only because unskilled workers' pay decreases. Better foreign innovation technology triggers an increase in the demand for skilled workers in the domestic country. In order to understand this channel, recall that the skilled labour market clearing condition $(29)$ can be written as $H\left(\theta_{0}^{D}\right)=$ $\left(I^{D} / A^{D}\right)^{1 /(1-\alpha)} x$, where $H\left(\theta_{0}^{D}\right)$ is the supply of skilled workers. A reduction in $A^{D} / A^{F}$ reduces $\theta_{0}^{D}$, thereby increasing $H\left(\theta_{0}^{D}\right)$ - since $d H\left(\theta_{0}^{D}\right) / d \theta_{0}^{D}=-\left(\theta_{0}^{D}-\gamma\right)$. For the market to clear, the increase in the supply of skilled workers must be matched by an equivalent increase in the demand. Dividing the steady-state innovation condition (33) by $I^{D}$ we obtain

$$
\frac{1}{q^{D}}=\frac{n}{\left(1-\phi_{1}\right)\left(\lambda^{\eta-1}-1\right)} \frac{1}{I^{D}} .
$$

Since the fraction of sectors monopolized by its firms $q^{D}$ decreases, $I^{D}$ must decrease and $I^{F}$ must increase by the same proportion, in order for their sum to be constant. Hence, since $H\left(\theta_{0}^{D}\right)$ increases and $I^{D}$ declines, for the skilled labour market to clear, the global innovation difficulty index $x$ must increase. The increase in innovation difficulty implies that to achieve an even smaller innovation success rate $I^{D}$, domestic firms must employ more workers in innovation. Notice that, as in the standard semi-endogenous Schumpeterian growth model (e.g. Segerstrom, 1998, Howitt, 1999), policy has only temporary effects on growth, with the long-run growth rate pinned down by population growth. Combining (33) and (26) we obtain the steady-state growth rate,

$$
g=\frac{\dot{Q}}{Q}=\frac{n}{1-\phi_{1}}
$$


An increase in innovation productivity $A^{F}$, increases $I^{F}$ as well as the global innovation intensity $I^{F}+I^{D}$ and the growth rate of quality but only along the transition to the steady state. The cumulated increase in aggregate quality level taking place along the transition implies that the global difficulty index $x=Q^{1-\phi} / N$ rises until the changes in $I^{F}$ and $I^{D}$ exactly offset each other. The skilled labour market clearing condition (29) tells us then that, due to the increase in innovation difficulty, the domestic country is forced to devote more labour resources to innovation, and this triggers and increase in skilled wages. ${ }^{22}$ We name this the global competition effect: stronger foreign competition for innovation makes it harder for domestic firms to innovate in the global economy, thus forcing them to devote more (skilled) labour to innovation.

Notice that by modelling a world economy in which both the leading country and the followers innovate, we generate international technology leapfrogging, which plays an important role in our results. The existing literature on technological competition between asymmetric countries focuses on North-South models where only the North innovates, while the South imitates. In these models, only one of our channels, business stealing, is present but it is triggered by a different economic mechanism; while the other, the global competition channel, does not feature. Business stealing takes place through an imitation mechanism: Southern firms copy Northern technologies and then exploit their lower production costs (lower wages) to force Northern firms out of business (see e.g. Helpman, 1993). There is no scope for technological leapfrogging where firms from both countries can conquer the global market introducing higher quality products. While these models are appropriate to study North-South competition, they do not capture the nature of competition between Japanese, European and American firms in the 1970s and 1980s, which is at the core of our paper. Having firms from both the leading and the follower country innovating is not only a necessary feature to model the type of competition we study, but it has also new theoretical implications. The global competition effect discussed above cannot be obtained in a model in which firms from the follower country can only copy frontier technologies. Imitation can affect innovation in the leading country only by reducing innovation costs (wages) but not by making global innovation races more competitive. ${ }^{23}$

Finally, because of the increase in the relative skilled wage $w_{H}^{D} / w_{L}^{D}$, skilled workers' time becomes more valuable, thus increasing the demand for service sector workers. The higher demand, in turns, attracts more unskilled workers into service occupation, thus increasing the ability cutoff $\theta_{L S}^{D}$. Since more people acquire education and become skilled ( $\theta_{0}^{D}$ is lower) and more unskilled workers choose to be employed in service occupations $\left(\theta_{L S}^{D}\right.$ is higher), the share of unskilled workers in production shrinks.

\footnotetext{
${ }^{22}$ Recall that our numeraire is the foreign unskilled wages, hence a reduction in $I^{D}$ must be interpreted as a decline in domestic innovation rate measured in terms of foreign unskilled wages.

${ }^{23}$ For examples of several applications of the North-South models see Bonfiglioli and Gancia (2008), Epifani and Gancia (2008), Parello (2008), and Borota (2012). Borota and Impullitti (2014) develop a North-South trade model with endogenous growth where Southern firms can innovate but only in those sectors in which there is FDI from the North.
} 
In order to keep the analysis tractable and derive the final set of properties of our model, we now assume that abilities are distributed uniformly. This assumption allows us to move from predicting the effects of changes in the technology gap on the relative wages per units of skills, to predicting the effects on average wages at the top, the middle, and the bottom of the skill distribution.

Proposition 3 Under a uniform distribution of abilities, $\Gamma\left(\theta_{0}^{K}\right)=\theta_{0}^{K}$, a reduction in the innovation technology gap $A^{D} / A^{F}$ widens wage polarization in the home country:

$i$. The wage of average skilled workers relative to that of average unskilled production workers, $\tilde{w}_{H}^{D} / \tilde{w}_{L}^{D}$, increases.

ii. The average wage of service sector workers relative to that of unskilled production workers, $\tilde{w}_{S}^{D} / \tilde{w}_{L}^{D}$, increases.

A formal proof of point $i$. is in the appendix. This is a key theoretical result of our model. The business-stealing and the global competition effects triggered by a reduction in the innovation technology gap increase the relative wage of skilled workers $w_{H}^{D} / w_{L}^{F}$. This increase triggers a change in the supply of skilled workers that could potentially offset its effect on the average skilled/unskilled wage ratio $\tilde{w}_{H}^{D} / \tilde{w}_{L}^{D}$. As more people acquire education (lower $\theta_{0}^{D}$ ), the average quality of skilled workers $\widetilde{\theta}_{H}^{D}$ declines. The increase in $\theta_{L S}^{D}$ together with the decrease in $\theta_{0}^{D}$ can potentially lead to a lower or a higher quality of unskilled workers in production. The relative strength of these forces determines the changes in the average quality of workers $\widetilde{\theta}_{H}^{D} \widetilde{\theta}_{L}^{D}$. The result above shows that, under uniform ability distribution, the overall effect of a reduction in the technology gap on wage inequality in the upper tail of the skill distribution, the $\tilde{w}_{H}^{D} / \tilde{w}_{L}^{D}$ ratio, is positive.

The second part of the proposition can be easily shown here. We can define the average wage of the unskilled workers employed in production as

$$
\tilde{w}_{L}^{D}=w_{L}^{D} \int_{\theta_{L S}^{D}}^{\theta_{0}^{D}} \theta \frac{d \Gamma(\theta)}{\Gamma\left(\theta_{0}^{D}\right)-\Gamma\left(\theta_{L S}^{D}\right)}=\frac{w_{L}^{D}}{2}\left(\theta_{0}^{D}+\theta_{L S}^{D}\right) .
$$

Similarly, the average wage of service sector workers is

$$
\tilde{w}_{S}^{D}=w_{L}^{D} \int_{0}^{\theta_{L S}^{D}} \theta \frac{d \Gamma(\theta)}{\Gamma\left(\theta_{0}^{D}\right)-\Gamma\left(\theta_{L S}^{D}\right)}=\frac{w_{L}^{D}}{2} \theta_{L S}^{D} .
$$

Hence the relative service sector wage is

$$
\omega_{S}=\frac{\tilde{w}_{S}^{D}}{\tilde{w}_{L}^{D}}=\left(\frac{1}{1+\frac{\theta_{0}^{D}}{\theta_{L S}^{D}}}\right) .
$$

Since an increase in $A^{F} / A^{D}$ decreases the cutoff $\theta_{0}^{D}$ and, by (8), increases $\theta_{L S}^{D}$, it is easy to see that $\partial \omega_{S} / \partial\left(A^{F} / A^{D}\right)>0$. Changes in the wage of service relative to production workers 
$\omega_{S}$ are pinned down by the effects on the average quality of workers in these different occupations. The increase in the cutoff $\theta_{L S}^{D}$, following the decline in the technology gap, increases the average quality of service workers $\widetilde{\theta}_{S}^{D}$, but the average quality of production workers could increase or decrease, as we saw above. With uniform ability distribution, the overall effect of lower technology gap on the relative service sector wage is positive. Hence, we can conclude that fiercer foreign technological competition brought about by a reduction in the innovation technology gap increases wage polarization, benefiting skilled workers and damaging workers in the middle of the skill distribution more than those at the bottom. ${ }^{24}$

\subsection{Globalization and the Wealth to Income ratio: A Schumpeterian View}

Besides the predictions on the evolution of personal wage inequality, which tracks wage difference across individuals, our theory has implications for a different dimension of inequality, the wealth to income ratio. As discussed in the motivation section, Piketty (2014), and Piketty and Zucman (2014) have provided evidence of increasing US wealth (capital) to income ratio in the period 1970-2010. They have also proposed an explanation of this change based on capital accumulation: the long-run wealth-income ratio tends to $s / g$, where $s$ is the saving rate net of capital depreciation and $g$ is the economy growth rate, the sum of productivity improvements of population growth. ${ }^{25}$ They suggest that the observed increase in the wealth to income ratio is mainly due to a decline in the growth rate. The reason is simple: if the economy accumulates capital in excess of depreciation ${ }^{26}$, the capital to income ratio grows if technological progress and population growth are not fast enough. For low $g$, even a moderate level of $s$ can determine a hypertrophic levels of capital. Piketty and Zucman (2014) claim that this is an accounting formula, holding in "the steady state of any micro-funded model, independently on the nature of the saving motive" (p.13). Besides the neoclassical growth model with exogenous and endogenous saving rate, they show that their equation can be obtained in many other models, such as, the bequest in the utility function model, the OLG model, etc.. Moreover, they claim but do not show, that it holds for most endogenous growth models. In these models, the argument goes, the saving rate can be affected by the growth rate, but its response is less than proportional, so that an increase in the growth rate would always reduce the wealth-income ratio. Hence, the negative relationship between growth accelerations and the wealth to income ratio holds also under endogenous growth. Because of its generality, Piketty's (2014) calls this

\footnotetext{
${ }^{24}$ Recall that the wage per unit of skills $w_{L}^{D}$ is the same in production and service sector occupations. And international competition has a negative effect on this wage.

${ }^{25}$ The wealth of a nation is defined as the sum of domestic capital plus net foreign assets. In an economy with a zero foreign assets position, the wealth to income ratio and the domestic capital to income ratio coincide. Domestic capital in the data is the sum of agricultural land, housing, the market value of corporations (equities) and the value of non-financial assets net of liabilities.

${ }^{26}$ According to their notation $Y$ is national income net of depreciation, while $s$ is the fraction of this income which goes to saving: hence it is not the usual Solow (1956) gross capital formation, but rather net capital formation.
} 
formula, the "second fundamental law" of capitalism.

In our Schumpeterian economy, country $D$ 's aggregate wealth, denoted $W^{D}$, coincides with the stock market value of all the profit-generating firms in the economy:

$$
W^{D}=\tilde{v}^{D} q^{D}
$$

where

$$
\tilde{v}^{D} \equiv \frac{\left(c^{D}+c^{F}\right)\left(\lambda-w_{L}^{D}\right)}{\rho\left(+\frac{n}{\left(1-\phi_{1}\right)\left(\lambda^{\eta-1}-1\right)}+\frac{n \phi_{1}}{1-\phi_{1}}\right) \lambda}
$$

is the value of a generic patent, that is of the monopolistic firm that owns it.

As in the classical Schumpeterian theory (Aghion and Howitt, 1992 and 1998), in our model the innovation free-entry condition (24) equates the expected value of a new patent with the unit cost of innovation, here represented by the wage of a skilled labour unit ${ }^{27}$. If we multiply both sides by the share of skilled workers in the economy, $H^{D}$ and use (29), the left hand side becomes the aggregate value of the flow of new patents and the right side the flow of savings in the economy, as shown in (41),

$$
\tilde{v}^{D} I^{D}=w_{H}^{D} H^{D}
$$

Since by (44) $I^{D}=q^{D} g \bar{\lambda}$, we can write

$$
\underbrace{\tilde{v}^{D} q^{D}}_{\text {Wealth }} g \bar{\lambda}=\underbrace{w_{H}^{D} H^{D}}_{\text {Savings }},
$$

where $\bar{\lambda}=\left(\lambda^{\eta-1}-1\right)^{-1}$ and $g$ given by (45) are constant. The budget constraint (41) implies that savings are $S^{D}=w_{H}^{D} H^{D}$, and expressing aggregate savings $S^{D}$ as the product of the marginal propensity to save multiplied by GDP, $S^{D}=s^{D} Y^{D}$, transforms (47) into:

$$
\tilde{\beta}^{D}=\frac{W^{D}}{Y^{D}}=\frac{s^{D}}{g \bar{\lambda}}
$$

which can be viewed as the Schumpeterian version of Piketty's "second fundamental law" of capitalism. Since in our semi-endogenous growth model the long-run growth rate is constant, the only difference with the baseline Piketty economy is that here the saving rate is endogenous. Hence, the wealth to income ratio increases only if aggregate saving increases. Since aggregate saving equals total investment in innovation, and the incentive to innovate is dictated by the market value of firms, the corporate wealth to income ratio is strictly increasing in innovation. Faster innovation in our economy has only transitional effects on growth which, as shown in (48), lead to persistently higher levels of saving and of the wealth-income ratio. As in all versions of the neoclassical growth model considered in Piketty and Zucman (2014), our exogenous longrun growth $g$ is pinned down by population growth, and in line with their prediction, we also

\footnotetext{
${ }^{27}$ Extending the model to the more general version - with both skilled and unskilled workers employed in innovation - used in our calibration would not change our argument.
} 
find that the wealth-income ratio increases when population growth slows down. However, in a key departure from their results, the endogenous growth engine of our Schumpeterian economy predicts a positive link between technological progress, growth and inequality. ${ }^{28}$ Hence, in line with Piketty and co-authors, a version of their formula holds in our Schumpeterian growth model. However, differently from their results, a temporary acceleration in the growth rate which leaves the steady state growth rate unchanged increases total saving and the wealth to income ratio.

Once we have established a general nexus between technological progress and the wealth to income ratio, we can study how globalization, the source of technological accelerations in our economy, affects this dimension of inequality.

Proposition 4 A reduction in the innovation technology gap $A^{D} / A^{F}$ raises country $D$ 's wealth to national income ratio $\tilde{\beta}^{D}$.

As shown above, the business stealing and the global efficiency effects combine to increase the demand for skilled workers and innovation spending. More investment in innovation implies more saving and higher stock market values of firms, leading to higher wealth-income ratio. Our theory proposes a Schumpeterian mechanism for the evolution of this fundamental ratio by explicitly obtaining the long-run growth rate from firms' innovation activities and endogenizing the consumption-saving decision. We also establish that globalization, in the form of stiffer foreign technological competition, can be a trigger of this mechanism and an important source of the wealth to income dynamics.

Summary of analytical results. We have shown analytically that if the innovation productivity of the foreign country increases, reducing the gap with the world technological leader, the leading country experiences the following changes:

i. A decrease in the range of sectors enjoying global primacy.

ii. An increases in inequality at the top of the skill distribution.

iii. A decrease in inequality at the bottom of the skill distribution.

iv. An increase in personal services employment.

v. A decline in production/manufacturing employment.

vi An increase in the aggregate wealth-income ratio.

\footnotetext{
${ }^{28}$ Krusell and Smith (2014), show that Piketty and co-authors choice to focus on net instead of gross variable is crucial for the robustness of the "second fundamental law". Since we do not have physical capital, in our economy there is no exogenous depreciation of wealth. Hence the distinction between net and gross variables disappears.
} 
Although the model is very stylized, it seems to capture the salient stylized facts of the US labour market documented by Autor and Dorn (2013) and Piketty and Zucman (2014) that we reported in Tables 1-2 and Figures 1-2, together with the evolution of the distribution of global patents shown in Figure 3. In the next section, we introduce additional important real world elements, which will help enrich the picture and allow us to move on to a quantitative assessment of our theory.

\section{Quantitative analysis}

In order to take the model to the data we generalize it along two dimensions. First, we remove the assumption that skilled workers are used only in innovation and unskilled only in production. Secondly, we assume away free trade introducing trade barriers in the form of iceberg costs. We then calibrate the parameters of the model to match some key statistics of the data discussed in section 2, compute the numerical solution using the calibrated parameters and explore the effects of our dimension of globalization on wage polarization and the wealth-income ratio.

\subsection{Generalizations}

We generalize the technology of our economy allowing skilled and unskilled workers to be employed in both production and innovation. The production technology becomes

$$
Z^{K}\left(w_{L}^{K}, w_{H}^{K}\right)=\left(1 / z^{K}\right)\left(w_{L}^{K}\right)^{\beta}\left(w_{H}^{K}\right)^{1-\beta}, \text { for } K=D, F
$$

The unit production cost in country $F$ is the numeraire, that is $Z^{F}\left(w_{L}^{F}, w_{H}^{F}\right) \equiv 1$. The innovation technology is

$$
F^{K}\left(w_{L}^{K}, w_{H}^{K} ; A^{K}\right) X(\omega)=\left(1 / A^{K}\right) X(\omega)\left(w_{L}^{K}\right)^{\varphi}\left(w_{H}^{K}\right)^{1-\varphi}, K=D, F .
$$

where the difficulty index $X(\omega)=q(\omega) / Q^{\phi}$ is the same as in the benchmark model. As in the previous sections the technology gap is captured by assuming $A^{D}>A^{F}$. The countryspecific production technology parameter $z^{K}$ is introduced for generality, and will not play any particular role besides that of contributing to the numerical fit of the model in the calibration.

Assumption 2. (Factor Intensity): $F_{H}^{K} / F_{L}^{K}>Z_{H}^{K} / Z_{L}^{K}$ : innovation is the skill intensive activity. With the Cobb-Douglas technologies above, the factor bias of innovation is pinned down by assuming $\beta>\varphi .^{29}$

This assumption implies less extreme factor intensity compared to the baseline model. As we will show, qualitatively it does not change the basic mechanisms: an increase in the incentive to

\footnotetext{
${ }^{29}$ This assumption guarantees a strictly concave transformation curve between the production of goods and innovation probabilities. Any parameter configuration wih $\beta \neq \varphi$ would avoid a linear transformation curve. The upside is that we do not need the congestion externality parameter $\alpha$ anymore, which can be set equal to zero at no loss.
} 
innovate will still increase the relative demand for skilled workers, and a reduction in a country's share of leadership will still reduce the relative demand for unskilled workers. Quantitatively, factor intensity parameters $\beta$ and $\varphi$ will be important to determine the size of these changes.

We also introduce trade barriers in the form of iceberg costs. Firms need to ship $\tau>1$ units of goods in order to sell one unit abroad. In the presence of trade costs, the "narrow gap" assumption becomes $\tau Z^{D}\left(w_{L}^{D}, w_{H}^{D}\right) / \lambda<Z^{F}\left(w_{L}^{F}, w_{H}^{F}\right)<Z^{D}\left(w_{L}^{D}, w_{H}^{D}\right)$. As in the basic model, this allows domestic leaders to overcome a higher production cost by supplying a higher quality good.

Trade costs complicate the optimal pricing of firms compared to the basic model. The optimal price choice of country $F$ firms selling their product domestically (that is, in country $F$ market) $p_{d}^{F}$, and the optimal pricing of country $D^{\prime} s$ exporting firms (that is, selling in country $F$ market) $p_{x}^{D}$ leads to the same limit pricing,

$$
p_{d}^{F}=\lambda Z^{F}\left(w_{L}^{F}, w_{H}^{F}\right)=\lambda=\lambda Z^{F}\left(w_{L}^{F}, w_{H}^{F}\right)=p_{x}^{D} .
$$

In fact, in both cases, the limit price is anchored to the quality jump, $\lambda$, times the unit cost of the world competitive fringe, which is country $F^{\prime} s$ production cost $Z^{F}=1$. Slightly more complex is the optimal strategy of firms selling in country $D$. In case $Z^{D}\left(w_{L}^{D}, w_{H}^{D}\right)>\tau$, the relevant competitive fringe would still be country $F$ firms able to enter with the previous version of the good. Then the optimal price choice of country $D$ firms selling their product domestically (that is, in country $D$ market) $p_{d}^{D}$ and the price choice of country $F$ exporting firms (that is, selling in country $D$ market) $p_{x}^{F}$ yield the same limit pricing,

$$
p_{d}^{D}=\tau \lambda Z^{F}\left(w_{L}^{F}, w_{H}^{F}\right)=\tau \lambda=\tau \lambda Z^{F}\left(w_{L}^{F}, w_{H}^{F}\right)=p_{x}^{F} .
$$

If instead $Z^{D}\left(w_{L}^{D}, w_{H}^{D}\right)<\tau$, the relevant competitive fringe in country $D$ market would be country $D$ firms able to enter with the previous version of the good. Consequently, the optimal price choice of country $D$ firms selling their product domestically and of country $F$ exporting firms leads to the same limit pricing,

$$
p_{d}^{D}=\lambda Z^{D}\left(w_{L}^{D}, w_{H}^{D}\right)=p_{x}^{F} .
$$

Finally, the two pricing strategies coincide in case $Z^{D}\left(w_{L}^{D}, w_{H}^{D}\right)=\tau$.

To stay close to the baseline model, in which only country $F$ firms effectively limit-price country $D$ firms, we add the assumption that firms in country $D$ have to pay a however small fixed cost $\varepsilon_{c}>0$ when they are competing with a quality leader of their own country. That is, the quality leader of country $D$ can create (an however small) additional cost to the domestic competitive fringe. For example, this could consist of small IPRs and legal barriers, distribution network and advertisement frictions, etc. We assume that this extra cost is entirely rebated to the consumers ${ }^{30}$. Since firms operate under instantaneous price competition, each

\footnotetext{
${ }^{30}$ This is just an innoquous simplification useful to eliminate $\varepsilon_{c}$ from all the equations. Otherwise we would
} 
top-quality producer country $D$ firm can then maximize its profits effectively being constrained only by threat of the foreign competitive fringe, not only if $Z^{D}\left(w_{L}^{D}, w_{H}^{D}\right) \geq \tau$ but also if $Z^{D}\left(w_{L}^{D}, w_{H}^{D}\right)<\tau .{ }^{31}$

Once we account for the different technologies and pricing strategies shown here, the rest of the model follows the same structure as the baseline framework. The detailed derivation can be found in the appendix. Next, we calibrate the model and explore its properties numerically.

\subsection{Calibration}

We assume that abilities are drawn from the cumulative distribution function $\Gamma(\theta)=\theta^{\varepsilon}$. This is a fairly general distribution function in $[0,1]$ : when $\varepsilon=1$, the ability is distributed uniformly in the population, when $0<\varepsilon<1$ the ability distribution is skewed towards low-ability workers, and for $\varepsilon>1$ the ability distribution is log concave. ${ }^{32}$ In the quantitative analysis, we explore the effects of the reduction of the international technology gap on inequality in the period 1980 to 2000. The calibration period is one year. We have 17 parameters to calibrate: $\eta, \rho, n, \lambda, V$, $T_{H}, \epsilon, \varepsilon, \gamma_{H}, A^{D}, A^{F}, z^{D}, z^{F}, \phi_{1}, \varphi, \beta$, and $\tau$.

Nine parameters $n, \lambda, V, T_{H}, \gamma_{H}, \phi_{1}, \tau, \eta, \rho$, have close counterparts in the economy so that their calibration is straightforward. We set $\lambda$ to 1.3, to match an average markup over the marginal cost of 30 per cent. Since the estimates of average sectorial mark-ups usually are in the interval $(0.1,0.4)$ (Basu 1996), we take a value within this range. We choose $n$ to match a population growth rate of 1.14 percent (Bureau of labour Statistics, 1999), the total schooling time $T_{H}=4$ to match the average years of college in the US, and the total working life $V=52$ to match a life expectancy at birth for cohorts turning 18 year old in 1979 of 70 years (National Vital Report Statistics, 2010). ${ }^{33}$ Autor and Dorn (2013) show that the labour share of the set of occupations that we classified as skilled is lower than 40 percent in the period of interest. We follow this evidence by choosing a threshold $\gamma_{H}=0.60$ to bound the share of skilled workers in our economy below 40 percent of the workforce. The current empirical literature provides a wide range of estimates for the elasticity of substitution between domestic and foreign goods. The "macro" elasticity between home and imported goods is in general smaller than the "micro" elasticity between foreign sources of imports. In a recent

have to keep track of this overhead cost of manufacturing, with no qualitative change in the results. Notice that since $\varepsilon_{c}$ can be arbitrarily small, it would not alter the calibration either, besides arbitrarily small rounding approximations.

${ }^{31}$ This assumption is not needed in the calibration, because parameters are still valid without the fixed costs. In fact, around the calibrated parameters $Z^{D}\left(w_{L}^{D}, w_{H}^{D}\right)>\tau$ holds anyway - even with $\varepsilon_{c}=0$. However, simulating the economy away enough from the calibrated parameters could at some point yield $Z^{D}\left(w_{L}^{D}, w_{H}^{D}\right)<\tau$, with consequent potential modification of the competitive environment of the industries.

${ }^{32}$ This distribution is often used in quantitative models with heterogeneous agents, to match wage, income and earning dispersion. See e.g. Chatterjie, Corbae, Nakajima, and Rios-Rull (2007), and Antunes, Cavalcanti, Villamil (2008).

${ }^{33}$ Agents choose whether to go to college at the age of 18, so that the 18 year old cohort in 1979 is represented by people born in 1961, and life expectancy at birth in 1961 in the US is 70 years. We also include retirement years into working life, by assuming that pensions are proportional (equal for simplicity) to wages during working life. 
paper, Feenstra, Obstfeld and Russ (2012), find that the median micro elasticity is 3.1, while the macro elasticity between home and imported goods is close to one. We take a value in this range and choose $\eta=1.2$, closer to the macro estimates. Corrado, Hulten and Sichel (2006) report an average growth of labour productivity of 1.17 percent a year in the period 1970-79. ${ }^{34}$ Since steady state growth is $g=n /\left(1-\phi_{1}\right)$, using this value for productivity growth and the population growth rate we can back out $\phi_{1}=0.0256$. We set $\rho$, which in steady state is equal to the interest rate $r$, to 0.03 to match the risk-free rate on treasury bills. Finally, we calibrate the iceberg trade cost parameter $\tau$ using recent estimates from Novy (2013), who derive a micro-founded measure of bilateral trade costs indirectly inferring trade frictions from observable trade data. The average tariff-equivalent US bilateral trade costs with its major trading partners is found to be $74 \%$ in 1970 , which corresponds to setting $\tau=1.74$ in our model. ${ }^{35}$ We normalize $A^{F}$ and $z^{F}$ to one without loss of generality.

We simultaneously choose the remaining parameters,

$$
\chi \equiv\left[\epsilon, \varphi, \beta, \varepsilon, A^{D}, z^{D}\right] \in \Xi
$$

so that the numerical steady-state solution of the model matches relevant statistics. The parameters are calibrated in order to minimize a loss function defined by the quadratic distance between the moments in the model and the targeted statistics. Technology parameters $\beta, \varphi$ and $z^{D}$ pin down the factor intensity of our economy and contribute to determine the relative wages $\tilde{w}_{H}^{D} / \tilde{w}_{L}^{D}$ and $\tilde{w}_{S}^{D} / \tilde{w}_{L}^{D}$. Hence we target Autor and Dorn (2013) relative wages reported in our Table 2: the 1980 value of ratio of the average skilled wage to average unskilled wage excluding services (1.276), the unskilled/service workers wage ratio (1.62), and the more standard skill premium, the average wage of skilled workers divided by the average wage of all unskilled workers, production plus service sector workers. The 1980 value obtained from Autor and Dorn data is 1.37. Moreover, parameters $\epsilon, \varepsilon$, together with $\beta$ and $\varphi$, are key in determining the occupational structure: the share of the workforce acquiring skills, the share of unskilled workers employed in production and the share of those employed in service activities. We use Autor and Dorn (2013) data targeting a share of skilled workers of $31 \%$ and a share of unskilled of $58 \% .^{36}$ The innovation productivity parameter $A^{D}$ is influential in determining the geographical distribution of patents, hence we target the average 1977-80 share of US patents in the US patent office (64\%) shown in the motivation section. ${ }^{37}$ Finally, we target the 1980 wealth-to-income ratio. The statistic consistent with our theoretical model is the Corporate

\footnotetext{
${ }^{34}$ In that paper they revise US national account data to introduce investment in intangible capital, a new, more comprehensive, measure of investment in innovation. Intangible capital includes R\&D, computer software, and investment in a set of activities aimed at improving existing goods, such as, advertising, design, marketing etc. The model we set up here does not have tangible (physical) capital, therefore national accounting statistics used in the calibration must be adapted to the model economy. Hence, the growth rate of productivity of $1.17 \%$ is obtained by subtracting the share attributable to tangible capital from the overall growth rate.

${ }^{35}$ The US major trading partners included in the estimation are, Germany, Japan, UK, Canada, Korea, and Mexico. The average US bilateral trade cost is obtained using bilateral trade volumes as weights.

${ }^{36}$ The share of service sectors workers can be obtained as a residual once these other two shares are computed.

${ }^{37}$ Notice that the sectorial production function for innnovation corresponding to cost functions $F^{D}$ and $F^{F}$
} 
Equity/National Income ratio taken from Piketty and Zucman (2014) and shown in our Figure 2 .

The calibration method is the following: define $\mathbf{m}=\left[m_{1}, \ldots, m_{8}\right]$ as the vector of the real data moments described above, and $y(\chi)$ the vector of equilibrium model moments generated by some vector of parameters $\chi$. Our calibrated parameter vector is obtained solving numerically

$$
\hat{\chi}=\underset{\chi \in \Xi}{\arg \min }\left[(y(\boldsymbol{\chi})-\mathbf{m}) \cdot W \cdot(y(\boldsymbol{\chi})-\mathbf{m})^{\prime}\right]
$$

where $W$ is the weighting matrix. We use a diagonal matrix with the squares of the data targets on the diagonal and zero for all other entries; formally $W_{i i}=1 / m_{i}^{2}$. The set of possible parameter values $\Xi$ contains the minimal restrictions of non-negativity and the bound between 0 and 1 for parameters $\epsilon, \varphi$, and $\beta$. The solution algorithm is as follow: for an initial vector of parameters, we solve the non-linear system of equations representing the steady-state equilibrium of our economy combining the set of algorithms in the Matlab fsolve function with the directed search method developed by Chris Sims and embedded in the csolve solver. The distance between model moments and data represented by the objective function above is minimized using a Nelder-Mead simplex algorithm. This procedure leads to the calibrated values listed in Table 3 .

Table 3. Calibrated Parameters

\begin{tabular}{lcl}
\hline \hline PARAMETER & SYMBOL & VALUE \\
\hline Service Efficiency & $\epsilon$ & 0.4339 \\
Ability Curvature & $\varepsilon$ & 6.582 \\
Unskill Intensity Production & $\beta$ & 0.512 \\
Unskill Intensity Innovation & $\varphi$ & 0.0234 \\
Innovation Technology & $A^{D}$ & 5.089 \\
Production Technology & $z^{D}$ & 1.5126 \\
\hline \hline
\end{tabular}

The fit of the calibrated model is shown in Table 4 ,

Table 4. Model Fit: 1980

\begin{tabular}{lclc}
\hline \hline TARGET & DATA & MODEL & FIT \% \\
\hline Skill/Unskilled Wage & 1.28 & 1.40 & $110 \%$ \\
Skill Premium & 1.369 & 1.469 & $107 \%$ \\
Unskilled/Service Wage & 1.62 & 1.39 & $86.2 \%$ \\
Skilled Workers \% & 0.315 & 0.30 & $95.3 \%$ \\
Unskilled Workers \% & 0.585 & 0.569 & $97.2 \%$ \\
Service Workers \% & 0.099 & 0.097 & $98.4 \%$ \\
US Patents \% & 0.63 & 0.63 & $100 \%$ \\
Wealth to income ratio & 0.67 & 0.67 & $100 \%$ \\
\hline \hline
\end{tabular}

is

$$
I^{K}=\frac{A^{K} \Omega}{X}\left(L^{K}\right)^{\varphi}\left(H^{K}\right)^{1-\varphi}
$$

where $\Omega=\varphi^{\varphi}(1-\varphi)^{1-\varphi}$. The value of the total factor productivity in innovation $A^{K}$ is then key in determining innovation output, which in the data we can proxy with patent counts. Hence, the US patent share, represented by $I^{D} / I^{F}$ in the model is a good target for the technology gap $A^{F} / A^{D}$. 
where we use unskilled workers (and wages) to indicate the non-educated workers employed outside personal service occupations (production and innovation), while service workers (and wages) refer to unskilled workers employed in services. The model captures fairly well most features of the data, providing a good fit of the targets.

\subsection{Globalization and wage polarization}

Here we show the effects of globalization, in the form of increasing foreign technological competition, on the wage and occupational structure. In the figure below, we report the effects of an increase in foreign innovation productivity $A^{F}$, which reproduces the reduction in the technology gap observed in the data. More precisely, we increase $A^{F}$ in order to match the reduction in the US share of patents from its benchmark value of $63 \%$ in 1977-80 to an average of about $53 \%$ in $1990-00$.
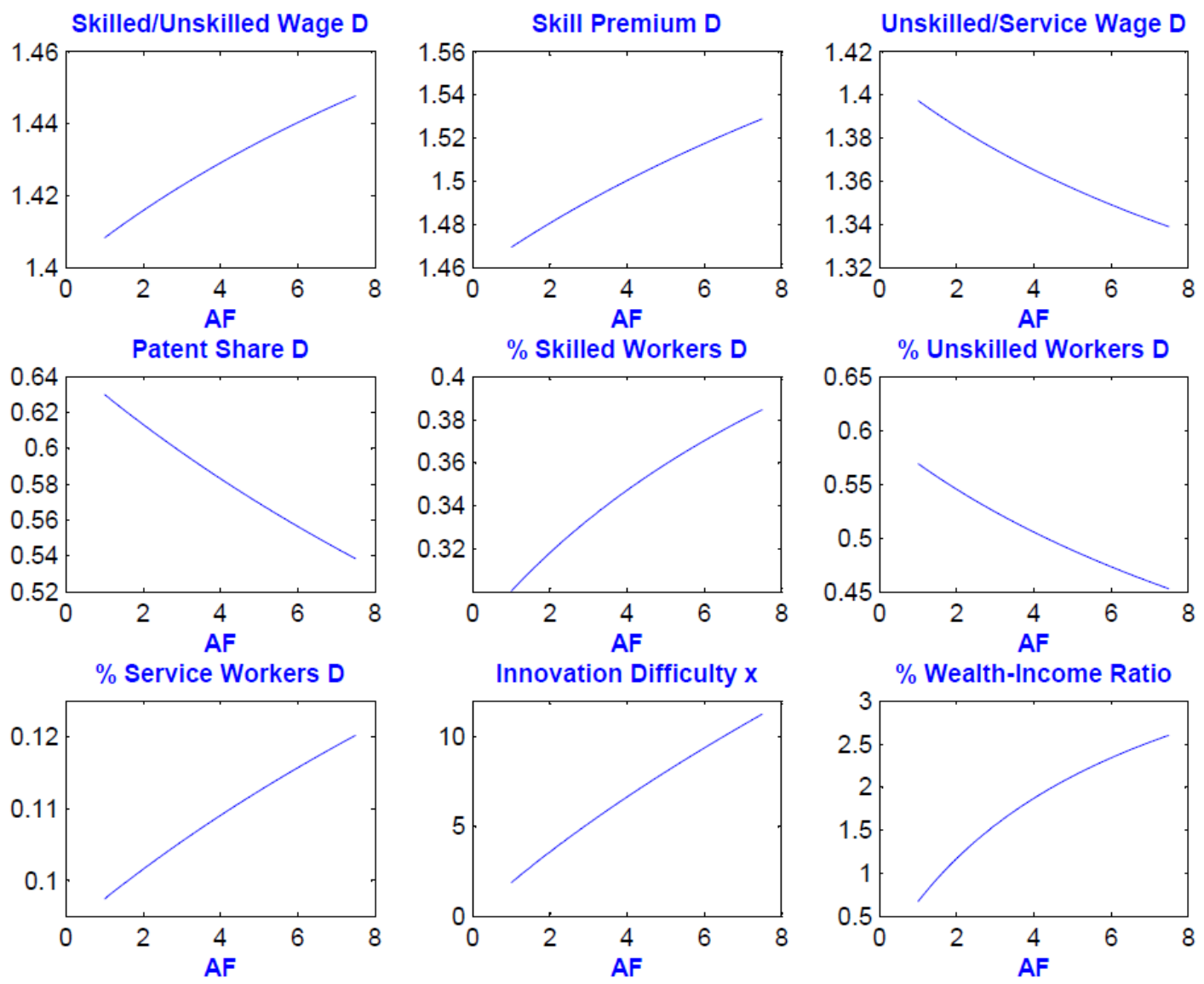

Figure 4. Technology Gap and Labour Market Polarization

The key analytical results of the baseline model seem to be confirmed in the numerical simulation of the generalized model: the shares of skilled and service sector workers increase while the share of unskilled workers (excluding services) decreases. Inequality at the top of 
the ability distribution, the skilled/unskilled relative wage, increases while inequality at the bottom, the unskilled/service wage ratio, decreases. Hence, the reduction in the technology gap reproduces qualitatively the polarization of US wages and occupations documented by Autor and Dorn (2013). The economic mechanisms connecting the technology gap and the wage structure are, as in the baseline model, the business stealing effect and global competition effect. The former can be observed in the reduction in the US patent share shown in Figure 4 , which in the model is represented by the share of sectors with domestic leadership $q^{D}$. The global competition effect can be seen in the sharp increase in the innovation difficulty index $x$.

Table 5 shows that quantitatively the reduction of the technology gap observed in the data can reproduce about $13 \%$ of the increase in wage inequality at the upper tails of the skill distribution (the skilled-unskilled wage ratio), about $26 \%$ of the decrease in inequality at the bottom of the skill distribution (service/unskilled ratio), and $23 \%$ of the increase in the skill premium documented by Autor and Dorn (2013). These results suggest that globalization, in the form of fiercer foreign technological competition, could be an important source of wage polarization. Certainly, other channels such as routine tasks-replacing technical change and other dimensions of globalization have contributed to the recent evolution of labour market polarization. Our mechanism provides a new channel complementing existing explanations of these important facts.

\begin{tabular}{llllll}
\hline \hline \multicolumn{5}{c}{ Table 5. } & Quantitative results \\
\hline \hline Moments & DATA & MoDEL & DATA & MODEL & CHANGE MATCHED \\
& $(1980)$ & $(1980)$ & $(2000)$ & $(2000)$ & \\
\hline Skill/Unskilled Wage & 1.28 & 1.40 & 1.494 & 1.447 & $13.4 \%$ \\
Skill Premium & 1.369 & 1.469 & 1.608 & 1.528 & $23.3 \%$ \\
Unskilled/Service Wage & 1.62 & 1.39 & 1.465 & 1.338 & $26.2 \%$ \\
Skilled Workers \% & 0.315 & 0.30 & 0,396 & 0.384 & $112 \%$ \\
Unskilled Workers \% & 0.585 & 0.569 & 0.487 & 0.452 & $123 \%$ \\
Service Workers \% & 0.099 & 0.097 & 0.115 & 0.120 & $137 \%$ \\
US Patents \% & 0.63 & 0.63 & 0.53 & 0.53 & $100 \%$ \\
Wealth to Income Ratio & 0.67 & 0.67 & 2.82 & 2.60 & $89.8 \%$ \\
\hline \hline
\end{tabular}

Finally, we find it surprising that, according to our simple model, the decline in the US relative technological primacy is enough to replicate a sizable share of the evolution of the wealth to income ratio documented by Piketty and Zucman (2014). Our economic mechanism operates through the two key forces highlighted before: first, an increase in the rest of the world competitiveness reduces the wage of the US unskilled workers - according to the business stealing effect - and raises US firms' profits. The rise in corporate profits boosts corporate equity, which is the bulk of wealth in our economy. Secondly, since stronger innovativeness worldwide leads to an increase in technological difficulty (our endogenous variable $x$ ), the expected discounted value of the profits of innovative firms has to be higher in order to repay 
for the higher cost of innovation - following the global competition effect highlighted before. Hence, stronger foreign competition makes it harder for firms to successfully innovate in the global marketplace, thereby triggering more investment in innovation and fuelling an increase in the wedge between profits/wealth and labour incomes.

Our theory supplements Piketty's analysis because wealth in our model is only represented by the market values of corporations, while we neglect agricultural land, residential investment, and all other non-financial assets that are important parts of wealth in the data. ${ }^{38} \mathrm{~A}$ more complete analysis should consider all these important aspects of the economy. Once the role of capital accumulation (in all its forms) and of all these other features of the real economy are taken into account, it is likely that the surprisingly high explanatory power of our mechanism would be reduced. We leave these interesting extensions to future research.

\section{Conclusion}

Technological catch-up with the United States economy has been a salient feature of the postWWII global economy. Several countries have increased their ability to compete with the US and successfully entered innovation races for global market leadership: Europe, Japan, and South Korea earlier, and more recently China. This catching-up process is in part reflected in a particular dimension of globalization we zero in on in this paper: lagging countries entering global innovation races and effectively competing with technological leaders. We focus on this form of globalization not only because it has been studied less extensively than other forms (i.e. declining trade barriers), but also because technological competition, as highlighted by Schumpeterian growth theory, is of key importance in shaping the long-run distribution of market leadership.

Our analysis shows that such technological globalization process plays a role in fuelling several dimensions of inequality. The decrease in relative competitiveness of the US innovation system as compared with the rest of the world determines an erosion of the US industrial base, which depresses the unskilled manufacturing wages and raises the remuneration of skilled workers. More innovation in the rest of the world also raises the difficulty of innovation. As innovation becomes harder, more resources must be devoted to it in order to compete in the global playfield, thus the demand for high skilled workers, which are used more intensively in innovation, increases together with their remuneration. As skilled labour time becomes more valuable, personal services that free labour time are more in demand, with consequent upward pressure on their wages and employment levels. Hence, globalization leads to wage polarization, to the advantage of the upper and lower tails of the skill distribution and to the detriment of occupations performed by workers with an intermediate level of skills. When matched to the US data, our model reproduces a non-negligible part of the increase in wage polarization occurred

\footnotetext{
${ }^{38}$ Bonnet, Bono, Chapelle, and Wasmer (2014) have recently shown that the housing price bubble is responsible for a substantial part of the recent increase in the wealth-income ratio in many countries.
} 
in the US in the 1980-2000 period.

An additional prediction is that more intense foreign technological competition increases the US wealth-income ratio, in line with the evidence in Piketty (2014) and Piketty and Zucman (2014): globalization increases corporate profits and the market value of leading firms by reducing labour costs and increasing the competition for global quality leadership. For this reason, inequality between labour and capital/wealth increases to the advantage of the latter. Since firms' profitability pins down the value of a patent in our Schumpeterian economy, globalization triggers more innovation, faster technological progress and more inequality. Unlike the great similarity between our result and Piketty's (2014) "second law of capitalism", our framework suggests that it is innovation and growth, rather than economic stagnation, the ultimate source of inequality.

\section{Appendix A: proofs}

Proof of Proposition 1.- Diving both skilled labour market clearing conditions (29) we obtain

$$
\frac{\widetilde{\theta}_{H}^{D}\left(\theta_{0}^{D}\right)\left(1-\Gamma\left(\theta_{0}^{D}\right)\right)}{\widetilde{\theta}_{H}^{F}\left(\theta_{0}^{F}\right)\left(1-\Gamma\left(\theta_{0}^{F}\right)\right)}=\left(\frac{I^{D} / I^{F}}{A^{D} / A^{F}}\right)^{1 /(1-\alpha)},
$$

which, using (53), can be rewritten as:

$$
\frac{\widetilde{\theta}_{H}^{D}\left(\theta_{0}^{D}\right)\left(1-\Gamma\left(\theta_{0}^{D}\right)\right)}{\widetilde{\theta}_{H}^{F}\left(\theta_{0}^{F}\right)\left(1-\Gamma\left(\theta_{0}^{F}\right)\right)}=\left(\frac{M^{D}\left(\theta_{0}^{D}\right) / M^{F}\left(\theta_{0}^{F}\right)}{A^{D} / A^{F}}\right)^{1 /(1-\alpha)}
$$

or

$$
\frac{A^{D}}{A^{F}}=\left[\frac{\widetilde{\theta}_{H}^{F}\left(\theta_{0}^{F}\right)\left(1-\Gamma\left(\theta_{0}^{F}\right)\right)}{\widetilde{\theta}_{H}^{D}\left(\theta_{0}^{D}\right)\left(1-\Gamma\left(\theta_{0}^{D}\right)\right)}\right]^{1-\alpha} \frac{M^{D}\left(\theta_{0}^{D}\right)}{M^{F}\left(\theta_{0}^{F}\right)} .
$$

The steady-state manufacturing labour market clearing condition for the domestic market is

$$
M\left(\theta_{0}^{D}\right) \equiv \int_{\theta_{L S}^{D}}^{\theta_{0}^{D}} \theta d \Gamma(\theta)=\frac{c^{D}+c^{F}}{\lambda} I_{n}^{D} /\left(I_{n}^{D}+I^{F}\right)
$$

where we have used the definition of $\widetilde{\theta}_{M}^{D}$ and (8) to substitute out $1-\Gamma\left(\theta_{H S}^{D}\right)$ and (36). Similarly for the foreign region we have

$$
M\left(\theta_{0}^{F}\right)=\int_{\theta_{L S}^{F}}^{\theta_{0}^{F}} \theta d \Gamma(\theta)=\frac{c^{D}+c^{F}}{\lambda} I^{F} /\left(I_{n}^{D}+I^{F}\right) .
$$

From the education choice (8) we obtain

$$
T\left(\theta_{H S}^{K}\right) \equiv \frac{\Gamma^{-1}\left(1-\Gamma\left(\theta_{H S}^{K}\right)\right)}{(1-\epsilon)\left(\theta_{H S}^{K}-\gamma_{H}\right)}=\frac{w_{H}^{K}}{w_{L}^{K}}=\sigma_{1}\left(\frac{\theta_{0}^{K}}{\theta_{0}^{K}-\gamma_{H}}\right)
$$


which implies that $\theta_{H S}^{K}$ is an increasing function of $\theta_{0}^{K}$, and therefore $\theta_{L S}^{K}$ is an decreasing in $\theta_{0}^{K}$. This allows us to establish that $d M\left(\theta_{0}^{K}\right) / d \theta_{0}^{K}=\theta_{0}^{K}-\theta_{0}^{K} d \theta_{L S}^{K} / d \theta_{0}^{K}>0$. Hence, $M\left(\theta_{0}^{K}\right)$ increasing in $\theta_{0}^{K}$. After dividing the two unskilled labour market clearing conditions, we obtain

$$
\frac{M^{D}\left(\theta_{0}^{D}\right)}{M^{F}\left(\theta_{0}^{F}\right)}=I^{D} / I^{F}
$$

Since $M\left(\theta_{0}^{K}\right)$ in (49) is increasing in $\theta_{0}^{K}, \theta_{0}^{D}>\theta_{0}^{F}$ must hold. Moreover eq. (53) implies $I^{D}>I^{F}$; hence $I^{F} /\left(I_{n}^{D}+I^{F}\right)=s_{D L}>1 / 2$.

Diving both sides of eq.s (34) and (35) gives:

$$
\frac{\lambda-w_{L}^{D}}{\lambda-1}\left(\frac{A^{D}}{A^{F}}\right)^{\frac{1}{1-\alpha}}\left(\frac{I^{F}}{I^{D}}\right)^{\frac{\alpha}{1-\alpha}}=w_{H}^{D} / w_{H}^{F},
$$

which can be rewritten as,

$$
\frac{1}{\lambda-1}\left(\frac{1}{w_{L}^{D}}-1\right)\left(\frac{A^{D}}{A^{F}}\right)^{\frac{1}{1-\alpha}}\left(\frac{I^{F}}{I^{D}}\right)^{\frac{\alpha}{1-\alpha}}=\left(w_{H}^{D} / w_{L}^{D}\right) / w_{H}^{F},
$$

or as

$$
\frac{1}{\lambda-1}\left(\frac{\lambda}{w_{L}^{D}}-1\right) \frac{\widetilde{\theta}_{H}^{F}\left(\theta_{0}^{F}\right)\left(1-\Gamma\left(\theta_{0}^{F}\right)\right)}{\widetilde{\theta}_{H}^{D}\left(\theta_{0}^{D}\right)\left(1-\Gamma\left(\theta_{0}^{D}\right)\right)} \frac{M^{D}\left(\theta_{0}^{D}\right)}{M^{F}\left(\theta_{0}^{F}\right)}=\left(w_{H}^{D} / w_{L}^{D}\right) / w_{H}^{F},
$$

in which we notice the following: since $\theta_{0}^{D}>\theta_{0}^{F}$ we must have

$$
\left[\frac{\tilde{\theta}_{H}^{F}\left(\theta_{0}^{F}\right)\left(1-\Gamma\left(\theta_{0}^{F}\right)\right)}{\widetilde{\theta}_{H}^{D}\left(\theta_{0}^{D}\right)\left(1-\Gamma\left(\theta_{0}^{D}\right)\right)}\right] \frac{M^{D}\left(\theta_{0}^{D}\right)}{M^{F}\left(\theta_{0}^{F}\right)}>1
$$

however, for (6), $\theta_{0}^{D}>\theta_{0}^{F}$ also implies $\left(w_{H}^{D} / w_{L}^{D}\right) / w_{H}^{F}<1$; in order to guarantee equality, the term $\left(\frac{1}{w_{L}^{D}}-1\right)$ must be lower than 1 , which only happens if $w_{L}^{D}>1=w_{L}^{F}$. Hence, $A^{D}>A^{F}$ implies $\theta_{0}^{D}>\theta_{0}^{F}$, which leads to $\left(w_{H}^{D} / w_{L}^{D}\right) / w_{H}^{F}<1$ and $w_{L}^{D}>1=w_{L}^{F}$.

Notice that eq. (33) and eq. (53) now imply that

$$
\begin{aligned}
I^{F} & =\frac{n}{\left(1-\phi_{1}\right)\left(\lambda^{\eta-1}-1\right)\left(\frac{M^{D}\left(\theta_{0}^{D}\right)}{M^{F}\left(\theta_{0}^{D}\right)}+1\right)} \text { and } \\
I^{D} & =\frac{n}{\left(1-\phi_{1}\right)\left(\lambda^{\eta-1}-1\right)\left(\frac{M^{F}\left(\theta_{0}^{D}\right)}{M^{D}\left(\theta_{0}^{D}\right)}+1\right)}
\end{aligned}
$$

Hence we can write:

$$
\frac{I^{D}}{I^{D}+I^{F}}=\frac{M^{D}\left(\theta_{0}^{D}\right)}{M^{D}\left(\theta_{0}^{D}\right)+M^{F}\left(\theta_{0}^{F}\right)}
$$

and

$$
\frac{I^{F}}{I^{D}+I^{F}}=\frac{M^{F}\left(\theta_{0}^{F}\right)}{M^{D}\left(\theta_{0}^{D}\right)+M^{F}\left(\theta_{0}^{F}\right)}
$$


The domestic unskilled labour market clearing conditions (50) and (51) can be written as

$$
\lambda\left[M^{D}\left(\theta_{0}^{D}\right)+M^{F}\left(\theta_{0}^{F}\right)\right]=c^{D}+c^{F} .
$$

The consumer budget constraint in country $F$ is:

$$
c^{F}=M^{F}\left(\theta_{0}^{F}\right) \frac{\theta_{0}^{F}}{2}+\frac{\left(c^{D}+c^{F}\right)(\lambda-1)}{\lambda} \frac{I^{F}}{I_{n}^{D}+I^{F}},
$$

according to which in the steady state the individuals consume the value of the unskilled wages and firm profits, while they save an amount equal to their innovation wage income. Plugging here the previous equations for $c^{D}+c^{F}$ and $I^{F}$ and $I_{n}^{D}$, we obtain:

$$
\begin{aligned}
& c^{F}=M^{F}\left(\theta_{0}^{F}\right)\left(\frac{\theta_{0}^{F}}{2}+\lambda-1\right), \text { which implies } \\
& c^{D}=M^{D}\left(\theta_{0}^{D}\right) \lambda+M^{F}\left(\theta_{0}^{F}\right)\left(1-\frac{\theta_{0}^{F}}{2}\right) .
\end{aligned}
$$

To simplify notation, from now on we will denote aggregate percapita domestic human capital as $H\left(\theta_{0}^{D}\right)$ and aggregate percapita foreign human capital as $H\left(\theta_{0}^{F}\right)$. Let now rewrite the skilled labour market conditions in the implicit form

$$
H\left(\theta_{0}^{D}\right)=\left(\frac{I^{D}}{A^{D}}\right)^{1 /(1-\alpha)} x
$$

and

$$
H\left(\theta_{0}^{F}\right)=\left(\frac{I^{F}}{A^{F}}\right)^{1 /(1-\alpha)} x
$$

where $x=Q^{1-\phi_{1}} / N$, and the per-capita supply of skills $H\left(\theta_{0}^{D}\right)=\widetilde{\theta}_{H}^{K}\left[1-\Gamma\left(\theta_{0}^{K}\right)\right] \phi$ is decreasing in the cutoff ability level $\theta_{0}^{D}$. We can rewrite the free entry conditions in innovation eq.s (34) and (35) as:

$$
\begin{aligned}
& \frac{\left[M^{D}\left(\theta_{0}^{D}\right)+M^{F}\left(\theta_{0}^{F}\right)\right]\left(\lambda-w_{L}^{D}\right)}{\rho+\frac{n}{\left(1-\phi_{1}\right)\left(\lambda^{\eta-1}-1\right)}+\frac{n \phi_{1}}{1-\phi_{1}}} A^{D} x^{-1}\left(\frac{I^{D}}{A^{D}}\right)^{\frac{-\alpha}{1-\alpha}}=w_{L}^{D} \sigma_{1}\left(\frac{\theta_{0}^{D}}{\theta_{0}^{D}-\gamma_{H}}\right), \\
& \frac{\left[M^{D}\left(\theta_{0}^{D}\right)+M^{F}\left(\theta_{0}^{F}\right)\right](\lambda-1)}{\rho+\frac{n}{\left(1-\phi_{1}\right)\left(\lambda^{\eta-1}-1\right)}+\frac{n \phi_{1}}{1-\phi_{1}}} A^{F} x^{-1}\left(\frac{I^{F}}{A^{F}}\right)^{\frac{-\alpha}{1-\alpha}}=\sigma_{1}\left(\frac{\theta_{0}^{F}}{\theta_{0}^{F}-\gamma_{H}}\right) .
\end{aligned}
$$

We solve for $x$ in eq. (60):

$$
x=H\left(\theta_{0}^{F}\right)\left(\frac{I^{F}}{A^{F}}\right)^{-1 /(1-\alpha)}
$$


which, plugged into free entry condition (62), and using eq. (56) and simplifying, becomes:

$$
\frac{\lambda-1}{\rho+\frac{n}{\left(1-\phi_{1}\right)\left(\lambda^{\eta-1}-1\right)}+\frac{n \phi_{1}}{1-\phi_{1}}} \frac{n}{\left(1-\phi_{1}\right)\left(\lambda^{\eta-1}-1\right)} \frac{M^{F}\left(\theta_{0}^{F}\right)}{H\left(\theta_{0}^{F}\right)}=\sigma_{1}\left(\frac{\theta_{0}^{F}}{\theta_{0}^{F}-\gamma_{H}}\right),
$$

in which the left hand side increases in $\theta_{0}^{F}$ - due to $M^{F}\left(\theta_{0}^{F}\right)$ being increasing and $H\left(\theta_{0}^{F}\right)$ decreasing in $\theta_{0}^{F}$ - which the right hand side decreases in $\theta_{0}^{F}$. Hence there is only one value of $\theta_{0}^{F} \equiv \bar{\theta}_{0}^{F}$ which solves this equations. Therefore eq. (64) implicitly defines the unique steady state equilibrium value of $\theta_{0}^{F}$ as a function of exogenous parameters:

$$
\theta_{0}^{F} \equiv \bar{\theta}_{0}^{F}\left(n, \rho, \lambda, \eta, \phi_{1}, \phi, \sigma\right) .
$$

Having proved the uniqueness of $\theta_{0}^{F}$ facilitates our proof of the uniqueness of $\theta_{0}^{D}$, and of all other endogenous variables, follows in a straightforward manner. In fact, the steady state equilibrium value of $\theta_{0}^{F}$ characterized here, along with (63), allows us to rewrite the domestic human capital equilibrium condition (59) as:

$$
H\left(\theta_{0}^{D}\right)=\left(\frac{I^{D}}{A^{D}}\right)^{1 /(1-\alpha)} H\left(\bar{\theta}_{0}^{F}\right)\left(\frac{I^{F}}{A^{F}}\right)^{-1 /(1-\alpha)},
$$

which, after using (53) can be written as:

$$
\left(\frac{A^{D}}{A^{F}}\right)^{1 /(1-\alpha)}=\left(\frac{1}{M^{F}\left(\bar{\theta}_{0}^{F}\right)}\right)^{1 /(1-\alpha)} \frac{H\left(\bar{\theta}_{0}^{F}\right)}{v\left(\theta_{0}^{D}\right)},
$$

where

$$
v\left(\theta_{0}^{D}\right) \equiv\left(\frac{1}{M^{D}\left(\theta_{0}^{D}\right)}\right)^{1 /(1-\alpha)} H\left(\theta_{0}^{D}\right) .
$$

Notice that $v^{\prime}\left(\theta_{0}^{D}\right)<0$. Hence, given $\bar{\theta}_{0}^{F}$, there is a unique value of $\theta_{0}^{D}$ which solves eq. (65). Therefore the steady state equilibrium of $\theta_{0}^{D}$ is unique, and it is given by

$$
\theta_{0}^{D}=v^{(-1)}\left[\left(\frac{1}{M^{F}\left(\bar{\theta}_{0}^{F}\right)}\right)^{1 /(1-\alpha)} H\left(\bar{\theta}_{0}^{F}\right)\left(\frac{A^{F}}{A^{D}}\right)^{1 /(1-\alpha)}\right] \equiv \bar{\theta}_{0}^{D}\left(\frac{A^{F}}{A^{D}}, n, r, \lambda, \eta, \phi_{1}, \phi, \sigma\right) .
$$

Using the previous equation to establish uniqueness of all the other endogenous variable is straightforward.

Proof of Proposition 2. Eq. (65) implies that

$$
\frac{\partial \bar{\theta}_{0}^{D}}{\partial\left(\frac{A^{F}}{A^{D}}\right)}<0
$$

Since for (6) the $w_{H}^{D} / w_{L}^{D}$ is decreasing in $\theta_{0}^{D}$, this implies that a lower technology gap leads to higher relative skilled wage. 
Recalling the domestic free entry condition (61), gives

$$
\frac{\left[M^{D}\left(\theta_{0}^{D}\right)+M^{F}\left(\theta_{0}^{F}\right)\right]\left(\lambda-w_{L}^{D}\right)}{\left(\rho+\frac{n}{\left(1-\phi_{1}\right)\left(\lambda^{\eta-1}-1\right)}+\frac{n \phi_{1}}{1-\phi_{1}}\right)} A^{D} x^{-1}\left(\frac{I^{D}}{A^{D}}\right)^{\frac{-\alpha}{1-\alpha}}=w_{L}^{D} \sigma_{1}\left(\frac{\theta_{0}^{D}}{\theta_{0}^{D}-\gamma_{H}}\right) .
$$

using (63) to substitute for $x$ in (67), multiplying and dividing by $I^{F}$, and rearranging the right hand side, we get to

$$
\begin{aligned}
& \frac{\left[M^{D}\left(\theta_{0}^{D}\right)+M^{F}\left(\theta_{0}^{F}\right)\right]\left(\eta_{1}-\left(\eta_{1}-1\right) w_{L}^{D}\right)}{\left(\rho+\frac{n}{\left(1-\phi_{1}\right)\left(\lambda^{\eta-1}-1\right)}+\frac{n \phi_{1}}{1-\phi_{1}}\right)\left(\eta_{1}-1\right)}\left(\frac{A^{D}}{A^{F}}\right)^{\frac{1}{1-\alpha}} \frac{I^{F}}{H\left(\theta_{0}^{F}\right)}\left(\frac{I^{F}}{I^{D}}\right)^{\frac{\alpha}{1-\alpha}} \\
= & \frac{\left(\eta_{1}-\left(\eta_{1}-1\right) w_{L}^{D}\right)\left(\frac{A^{D}}{A^{F}}\right)^{\frac{1}{1-\alpha}}}{\left(\rho+\frac{n}{\left(1-\phi_{1}\right)\left(\lambda^{\eta-1}-1\right)}+\frac{n \phi_{1}}{1-\phi_{1}}\right)\left(\eta_{1}-1\right)} \frac{n M^{F}\left(\theta_{0}^{F}\right)\left(\frac{M^{F}\left(\theta_{0}^{F}\right)}{M^{D}\left(\theta_{0}^{D}\right)}\right)^{\frac{\alpha}{1-\alpha}}}{H\left(\theta_{0}^{F}\right)\left(1-\phi_{1}\right)\left(\lambda^{\eta-1}-1\right)},
\end{aligned}
$$

where we have also used $(56)$ and (53) to eliminate $I^{F}$. Hence, after solving $(65)$ for $\left(\frac{A^{D}}{A^{F}}\right)^{1 /(1-\alpha)}$, the whole free entry condition (61) can be rewritten as:

$$
\frac{\frac{\eta_{1}}{w_{L}^{D}}-\left(\eta_{1}-1\right)}{\left(\rho+\frac{n}{\left(1-\phi_{1}\right)\left(\lambda^{\eta-1}-1\right)}+\frac{n \phi_{1}}{1-\phi_{1}}\right)\left(\eta_{1}-1\right)} \frac{n}{\left(1-\phi_{1}\right)\left(\lambda^{\eta-1}-1\right)} \frac{M^{D}\left(\theta_{0}^{D}\right)}{H\left(\theta_{0}^{D}\right)}\left(\frac{\theta_{0}^{D}-\gamma_{H}}{\theta_{0}^{D}}\right)=\sigma_{1},
$$

which, by the implicit function theorem, implies that

$$
\frac{\partial w_{L}^{D}}{\partial\left(\theta_{0}^{D}\right)}>0
$$

and therefore, since due to (66) $\theta_{0}^{D}$ is decreasing in $A^{F} / A^{D}$, we obtain

$$
\frac{\partial w_{L}^{D}}{\partial\left(\frac{A^{F}}{A^{D}}\right)}<0
$$

We have established that an increase in $A^{F} / A^{D}$ reduces $\theta_{0}^{D}$.

This completes the proof of part (i) of the Proposition.

Using result (i) and (53) we can establish

$$
\frac{\partial\left(\frac{I^{F}}{I^{D}}\right)}{\partial\left(\frac{A^{F}}{A^{D}}\right)}=\frac{\partial\left(\frac{\bar{\theta}_{0}^{F}}{\bar{\theta}_{0}^{D}}\right)}{\partial\left(\frac{A^{F}}{A^{D}}\right)}>0
$$

thus proving part (ii). Finally, (8) and (9), allows us to conclude that lower $A^{F} / A^{D}$ lead to lower $\theta_{H S}^{D}$ and higher $\theta_{L S}^{K}$, which completes the proof of part (iii). 
Proof of Proposition 3. The average wage of the skilled workers is

$$
\begin{aligned}
\tilde{w}_{H}^{D} & =w_{H}^{D} \frac{1}{1-\Gamma\left(\theta_{0}^{D}\right)}\left[(2-\epsilon) \int_{\theta_{H S}^{D}}^{1}\left(\theta-\gamma_{H}\right) d \Gamma(\theta)+\int_{\theta_{0}^{D}}^{\theta_{H S}^{D}}\left(\theta-\gamma_{H}\right) d \Gamma(\theta)\right] \\
& =\frac{w_{H}^{D}}{1-\theta_{0}^{D}}\left[(2-\epsilon)\left(\frac{1}{2}-\gamma_{H}\right)-(1-\epsilon)\left(\frac{\left(\theta_{H S}^{D}\right)^{2}}{2}-\gamma_{H} \theta_{H S}^{D}\right)-\frac{\left(\theta_{0}^{D}\right)^{2}}{2}+\gamma_{H} \theta_{0}^{D}\right] .
\end{aligned}
$$

The average wage of the unskilled workers is

$$
\tilde{w}_{L}^{D}=w_{L}^{D} \int_{0}^{\theta_{0}^{D}} \theta \frac{d \Gamma(\theta)}{\Gamma\left(\theta_{0}^{D}\right)}=\frac{w_{L}^{D}}{2} \theta_{0}^{D}
$$

Taking the ratio we can write the write the skilled-unskilled (production) wage ratio as

$\omega_{H}=\frac{\tilde{w}_{H}^{D}}{\tilde{w}_{L}^{D}}=2 \sigma_{1} \frac{1}{\left(1-\theta_{0}^{D}\right)\left(\theta_{0}^{D}-\gamma_{H}\right)}\left[(2-\epsilon)\left(\frac{1}{2}-\gamma_{H}\right)-(1-\epsilon)\left(\frac{\left(\theta_{H S}^{D}\right)^{2}}{2}-\gamma_{H} \theta_{H S}^{D}\right)-\frac{\left(\theta_{0}^{D}\right)^{2}}{2}+\gamma_{H} \theta_{0}^{D}\right]$

Notice that the numerator decreases in $\theta_{0}^{D}$ - because $\theta_{0}^{D}>\gamma_{H}$ and $d \theta_{H S}^{D} / d \theta_{0}^{D}>0$ - which the denominator increases in $\theta_{0}^{D}$ as long as $\theta_{0}^{D}<\left(1+\gamma_{H}\right) / 2$, which always holds in the US data we use. Therefore, we have $d \omega_{H} / d \theta_{0}^{D}<0$. Since we have already proved that $\partial \theta_{0}^{D} / \partial\left(A^{F} / A^{D}\right)<0$, it follows that an increase in $A^{F} / A^{D}$ increases the average relative skilled wage $\omega_{H}$.

\section{Proof of Proposition 4.}

Using eq. (33), eq. (46) becomes

$$
W^{D}=\frac{\left(c^{D}+c^{F}\right)\left(\lambda-w_{L}^{D}\right)}{\left(\rho+\frac{n}{\left(1-\phi_{1}\right)\left(\lambda^{\eta-1}-1\right)}+\frac{n \phi_{1}}{1-\phi_{1}}\right) \lambda} q^{D}=w_{H}^{D}\left[\frac{\left(I^{D}\right)^{\alpha}}{A^{D}}\right]^{1(/ 1-\alpha)} x .
$$

Using (29) and (44), net income $Y^{D}=\left(c^{D}+c^{F}\right) q^{D}+w_{H}^{D} H^{D}$ can be expressed as

$$
Y^{D}=\left(c^{D}+c^{F}\right) q^{D}+\frac{n q^{D}}{\left(1-\phi_{1}\right)\left(\lambda^{\eta-1}-1\right)} w_{H}^{D}\left[\frac{\left(I^{D}\right)^{\alpha}}{A^{D}}\right]^{1(/ 1-\alpha)} x .
$$

Dividing the last two expressions and simplifying, we obtain:

$$
\frac{Y^{D}}{W^{D}}=\frac{\left(\rho+\frac{n}{\left(1-\phi_{1}\right)\left(\lambda^{\eta-1}-1\right)}+\frac{n \phi_{1}}{1-\phi_{1}}\right) \lambda}{\left(\lambda-w_{L}^{D}\right)}+\frac{n q^{D}}{\left(1-\phi_{1}\right)\left(\lambda^{\eta-1}-1\right)}
$$

which increases in $w_{L}^{D}$, which in turn is a decreasing function of $A^{F}$ as proved in Proposition 2. 


\section{Appendix B: derivations of the generalized model}

Using the same notation as in Section 7.1, the equilibrium price choices of firms in country $D$ and in country $F$ are summarized by the following:

$$
\begin{gathered}
p_{d}^{D}(\omega)=p_{x}^{F}(\omega)=\min \left[\lambda Z^{D}\left(w_{L}^{F}, w_{H}^{F}\right), \lambda \tau\right] . \\
p_{d}^{F}(\omega)=p_{x}^{D}(\omega)=\lambda Z^{F}\left(w_{L}^{F}, w_{H}^{F}\right)=\lambda>1 \text { and }
\end{gathered}
$$

Therefore the prices paid by country $D$ consumers depend on whether $Z^{D}\left(w_{L}^{D}, w_{H}^{D}\right)>\tau$ holds. When it holds, it must be

$$
p_{d}^{D}(\omega)=\tau \lambda Z^{F}\left(w_{L}^{F}, w_{H}^{F}\right)=\tau \lambda \quad \text { and } \quad p_{x}^{F}(\omega)=\tau \lambda
$$

with resulting price indexes given by

$$
P^{D(\eta-1)}=\frac{(\lambda \tau)^{\eta-1}}{Q} \quad \text { and } \quad P^{F(\eta-1)}=\frac{\lambda^{\eta-1}}{Q} .
$$

If instead $Z^{D}\left(w_{L}^{D}, w_{H}^{D}\right)<\tau$, then

$$
p_{d}^{D}(\omega)=\lambda Z^{D}\left(w_{L}^{D}, w_{H}^{D}\right) \quad \text { and } \quad p_{x}^{F}(\omega)=\lambda Z^{D}\left(w_{L}^{D}, w_{H}^{D}\right)
$$

with resulting price indexes given by

$$
P^{D(\eta-1)}=\frac{\lambda Z^{D}\left(w_{L}^{D}, w_{H}^{D}\right)^{\eta-1}}{Q} \quad \text { and } \quad P^{F(\eta-1)}=\frac{\lambda^{\eta-1}}{Q} .
$$

These results will affect all other steady state equilibrium conditions, as we will see more in detail now.

Case $Z^{D}\left(w_{L}^{D}, w_{H}^{D}\right)>\tau$. In this case, the demand function for a domestic firm on the domestic market is

$$
d_{d}^{D}(\omega)=\frac{c^{D} q(\omega) P^{D(\eta-1)}}{p_{d}^{D}(\omega)^{\eta}}=\frac{c^{D} q(\omega)}{\lambda \tau Q}
$$

and its demand on the export market is

$$
d_{x}^{D}(\omega)=\frac{c^{F} q(\omega) P^{F(\eta-1)}}{p_{d}^{D}(\omega)^{\eta}}=\frac{c^{F} q(\omega)}{\lambda Q} .
$$

Similarly we can derive the demand for the foreign firm, $d_{d}^{F}(\omega)=c^{F} q(\omega) / \lambda Q$ and $d_{x}^{F}(\omega)=$ $c^{D} q(\omega) / \lambda \tau Q$. Equilibrium profits for domestic sales are

$$
\pi_{d}^{D}=\left(p_{d}^{D}-Z^{D}\right) d_{d}^{D}(\omega)=\left(1-\frac{Z^{D}}{\lambda \tau}\right) \frac{c^{D} q(\omega) N}{Q}
$$


and

$$
\pi_{x}^{D}=\left(p_{x}^{D}-\tau Z^{D}\right) d_{x}^{D}(\omega)=\left(1-\frac{Z^{D} \tau}{\lambda}\right) \frac{c^{F} q(\omega) N}{Q}
$$

on exports, and the $\pi^{D}=\pi_{d}^{D}+\pi_{x}^{D}$ represents total profits of a domestic firms. Similarly for a foreign firm we obtain

$$
\pi_{d}^{F}=\left(1-\frac{1}{\lambda}\right) \frac{c^{F} q(\omega) N}{Q}
$$

and

$$
\pi_{x}^{F}=\left(1-\frac{\tau}{\lambda \tau}\right) \frac{c^{D} q(\omega) N}{Q}=\left(1-\frac{1}{\lambda}\right) \frac{c^{D} q(\omega) N}{Q} .
$$

The free entry condition in innovation races is $v^{K}(\omega)=F^{K}\left(w_{L}^{K}, w_{H}^{K}\right) X(\omega)$, which leads to

$$
\begin{aligned}
& \frac{\left(1-\frac{Z^{D}}{\lambda \tau}\right) c^{D}+\left(1-\frac{Z^{D} \tau}{\lambda}\right) c^{F}}{r+I^{D}+I^{F}+n \phi_{1} /\left(1-\phi_{1}\right)} \frac{1}{x}=F^{D}\left(w_{L}^{D}, w_{H}^{D}\right) \\
& \frac{\left(1-\frac{1}{\lambda}\right)\left(c^{F}+c^{D}\right)}{r+I^{D}+I^{F}+n \phi_{1} /\left(1-\phi_{1}\right)} \frac{1}{x}=F^{F}\left(w_{L}^{F}, w_{H}^{F}\right)
\end{aligned}
$$

where $x=Q^{1-\phi} / N$.

labour market clearing conditions for unskilled workers are:

$$
\left[\Gamma\left(\theta_{0}^{D}\right)-\left(1-\Gamma\left(\theta_{H S}^{D}\right)\right)\right] \widetilde{\theta}_{M}^{D}=\frac{q^{D} Z_{L}^{D}}{\lambda}\left(\frac{c^{D}}{\tau}+\tau c^{F}\right)+I^{D} x F_{L}^{D}
$$

for the domestic country, and

$$
\left[\Gamma\left(\theta_{0}^{F}\right)-\left(1-\Gamma\left(\theta_{H S}^{F}\right)\right)\right] \widetilde{\theta}_{M}^{F}=\left(1-q^{D}\right) \frac{Z_{L}^{F}}{\lambda}\left(c^{F}+c^{D}\right)+I^{F} x F_{L}^{F}
$$

for the foreign country.

labour market clearing for skilled workers are

$$
\widetilde{\theta}_{H}^{D}\left(1-\Gamma\left(\theta_{0}^{D}\right) \phi=q^{D} \frac{Z_{H}^{D}}{\lambda}\left(\frac{c^{D}}{\tau}+\tau c^{F}\right)+I^{D} x F_{H}^{D}\right.
$$

and

$$
\widetilde{\theta}_{H}^{F}\left(1-\Gamma\left(\theta_{0}^{F}\right) \phi=\left(1-q^{D}\right) \frac{Z_{H}^{F}}{\lambda}\left(c^{F}+c^{D}\right)+I^{F} x F_{H}^{F} .\right.
$$

The national budget constraints determine consumption in both countries,

$$
\begin{aligned}
c^{D} & =q^{D}\left[\left(\frac{c^{D}}{\tau}+c^{F} \tau\right) \frac{Z_{L}^{D} w_{L}^{D}+Z_{H}^{D} w_{H}^{D}}{\lambda}+c^{D}\left(1-\frac{Z^{D}}{\lambda \tau}\right)+c^{F}\left(1-\frac{Z^{D} \tau}{\lambda}\right)\right] \\
& =q^{D}\left(c^{D}+c^{F}\right), \\
c^{F} & =q^{F}\left(c^{D}+c^{F}\right)\left[\frac{Z_{L}^{F} w_{L}^{F}+Z_{H}^{F} w_{H}^{F}}{\lambda}+\left(1-\frac{1}{\lambda}\right)\right] \\
& =q^{F}\left(c^{D}+c^{F}\right),
\end{aligned}
$$


where we used $Z_{L}^{D} w_{L}^{D}=\beta Z^{D}, Z_{H}^{D} w_{H}^{D}=(1-\beta) Z^{D}, Z_{L}^{F} w_{L}^{F}=\beta$, and $Z_{H}^{F} w_{H}^{F}=1-\beta$ to simplify these expressions, which implode to the unique equation:

$$
\frac{c^{D}}{q^{D}}=\frac{c^{F}}{q^{F}}
$$

The rest is the same as in the benchmark. The steady state equilibrium system is characterized by 13 unknowns, $c^{D}, c^{F}, I^{D}, I^{F}, w_{L}^{D}, w_{H}^{D}, w_{H}^{F}, \theta_{0}^{D}, \theta_{0}^{F}, \theta_{H S}^{D}, \theta_{H S}^{F}, q^{D}, x$ and 13 equations (6), (9),(73), (74), (75), (76), (77), (78), (33),(36), and (81).

Case $Z^{D}\left(w_{L}^{D}, w_{H}^{D}\right)<\tau$. This case is identical to the previous case, under our assumption of a positive (however small) fixed cost for country $D$ competitive fringe firms. This is what we follow in our simulations, to constrain the generalised model to follow the model in the text more closely - that is by imposing that the relevant competitive fringe is country F's. However, we can easily delineate what would happen in case the competitive fringe's fixed cost was zero in both countries. In this case, the demand function for a domestic firm on the domestic market is

$$
d_{d}^{D}(\omega)=\frac{c^{D} q(\omega) P^{D(\eta-1)}}{p_{d}^{D}(\omega)^{\eta}}=\frac{c^{D} q(\omega)}{\lambda Z^{D} Q}
$$

and its demand on the export market is

$$
d_{x}^{D}(\omega)=\frac{c^{F} q(\omega) P^{F(\eta-1)}}{p_{d}^{D}(\omega)^{\eta}}=\frac{c^{F} q(\omega)}{\lambda Q} .
$$

Similarly we can derive the demand for the foreign firm.

Equilibrium profits for domestic sales are

$$
\pi_{d}^{D}=(\lambda-1) Z^{D} d_{d}^{D}(\omega)=\left(1-\frac{1}{\lambda}\right) \frac{c^{D} q(\omega) N}{Q}
$$

and

$$
\pi_{x}^{D}=\left(\lambda-\tau Z^{D}\right) d_{x}^{D}(\omega)=\left(1-\frac{Z^{D} \tau}{\lambda}\right) \frac{c^{F} q(\omega) N}{Q}
$$

on exports, and the $\pi^{D}=\pi_{d}^{D}+\pi_{x}^{D}$ represents total profits of a domestic firms. Similarly for a foreign firm we obtain

$$
\pi_{d}^{F}=\left(1-\frac{1}{\lambda}\right) \frac{c^{F} q(\omega) N}{Q}
$$

and

$$
\pi_{x}^{F}=\left(1-\frac{\tau}{\lambda Z^{D}}\right) \frac{c^{D} q(\omega) N}{Q} .
$$

The free entry condition in innovation races is $v^{K}(\omega)=F^{K}\left(w_{L}^{K}, w_{H}^{K}\right) X(\omega)$, which leads to

$$
\frac{\left(1-\frac{1}{\lambda}\right) c^{D}+\left(1-\frac{Z^{D} \tau}{\lambda}\right) c^{F}}{r+I^{D}+I^{F}+n \phi_{1} /\left(1-\phi_{1}\right)} \frac{1}{x}=F^{D}\left(w_{L}^{D}, w_{H}^{D}\right)
$$




$$
\frac{\left(1-\frac{1}{\lambda}\right) c^{F}+\left(1-\frac{\tau}{\lambda Z^{D}}\right) c^{D}}{r+I^{D}+I^{F}+n \phi_{1} /\left(1-\phi_{1}\right)} \frac{1}{x}=F^{F}\left(w_{L}^{F}, w_{H}^{F}\right)
$$

where $x=Q^{1-\phi} / N$.

labour market clearing conditions for unskilled workers are:

$$
\left[\Gamma\left(\theta_{0}^{D}\right)-\left(1-\Gamma\left(\theta_{H S}^{D}\right)\right)\right] \widetilde{\theta}_{M}^{D}=\frac{q^{D} Z_{L}^{D}}{\lambda}\left(\frac{c^{D}}{Z^{D}}+\tau c^{F}\right)+I^{D} x F_{L}^{D}
$$

for the domestic country, and

$$
\left[\Gamma\left(\theta_{0}^{F}\right)-\left(1-\Gamma\left(\theta_{H S}^{F}\right)\right)\right] \widetilde{\theta}_{M}^{F}=\left(1-q^{D}\right) \frac{Z_{L}^{F}}{\lambda}\left(c^{F}+\frac{\tau}{Z^{D}} c^{D}\right)+I^{F} x F_{L}^{F} .
$$

for the foreign country. labour market clearing for skilled workers are

$$
\widetilde{\theta}_{H}^{D}\left(1-\Gamma\left(\theta_{0}^{D}\right) \phi=q^{D} \frac{Z_{H}^{D}}{\lambda}\left(\frac{c^{D}}{Z^{D}}+\tau c^{F}\right)+I^{D} x F_{H}^{D}\right.
$$

and

$$
\tilde{\theta}_{H}^{F}\left(1-\Gamma\left(\theta_{0}^{F}\right) \phi=\left(1-q^{D}\right) \frac{Z_{H}^{F}}{\lambda}\left(c^{F}+\frac{\tau}{Z^{D}} c^{D}\right)+I^{F} x F_{H}^{F} .\right.
$$

The national budget constraints determine consumption in both countries,

$$
\begin{aligned}
c^{D} & =q^{D}\left[\left(\frac{c^{D}}{Z^{D}}+c^{F} \tau\right) \frac{Z_{L}^{D} w_{L}^{D}+Z_{H}^{D} w_{H}^{D}}{\lambda}+\left(1-\frac{1}{\lambda}\right) c^{D}+\left(1-\frac{Z^{D} \tau}{\lambda}\right) c^{F}\right] \\
& =q^{D}\left(c^{D}+c^{F}\right), \\
c^{F} & =q^{F}\left[\left(c^{F}+\frac{\tau}{Z^{D}} c^{D}\right) \frac{Z_{L}^{F} w_{L}^{F}+Z_{H}^{F} w_{H}^{F}}{\lambda}+\left(1-\frac{1}{\lambda}\right) c^{F}+\left(1-\frac{\tau}{\lambda Z^{D}}\right) c^{D}\right] \\
& =q^{F}\left(c^{D}+c^{F}\right),
\end{aligned}
$$

where we used $Z_{L}^{D} w_{L}^{D}=\beta Z^{D}, Z_{H}^{D} w_{H}^{D}=(1-\beta) Z^{D}, Z_{L}^{F} w_{L}^{F}=\beta$, and $Z_{H}^{F} w_{H}^{F}=1-\beta$ to simplify these expressions, which implode to the unique equation:

$$
\frac{c^{D}}{q^{D}}=\frac{c^{F}}{q^{D}}
$$

The rest is the same as in the benchmark. The steady state equilibrium system is characterized by 13 unknowns, $c^{D}, c^{F}, I^{D}, I^{F}, w_{L}^{D}, w_{H}^{D}, w_{H}^{F}, \theta_{0}^{D}, \theta_{0}^{F}, \theta_{H S}^{D}, \theta_{H S}^{F}, q^{D}, x$ and 13 equations (6), (9), (82), (83), (84), (85), (86), (87), (33), (36), and (91).

\section{References}

[1] Acemoglu, D. (2003). "Patterns of Skill Premia", Review of Economic Studies, volume 70, pp. 199-230. 
[2] Acemoglu, D., and D. Autor (2011), "Skills, Tasks and Technologies:Implications for Employment and Earnings", Handbook of Labor Economics, Volume 4, Orley Ashenfelter and David E. Card (eds.), Amsterdam: Elsevier, 2011.

[3] Aghion P., and P. Howitt (1992). "A Model of Growth through Creative Destruction", Econometrica 60(2): 323-351.

[4] Aghion P., and P. Howitt (1998), Endogenous Growth Theory, MIT Press.

[5] Aghion P., and P. Howitt (2009), The Economics of Growth, MIT Press.

[6] Akcigit, U., S. Ates, G. Impullitti (2014). "Technology Dynamics, Innovation Policy and the Gains from Globalization", mimeo.

[7] Antunes, A., T. Cavalcanti, and A Villamil, (2008). "The Effect of Financial Repression \& Enforcement on Entrepreneurship and Economic Development," Journal of Monetary Economics, 55 (2): 278-297.

[8] Autor D. and D. Dorn (2013). "The Growth of Low-Skill Service Jobs and the Polarization of the US Labor Market", American Economic Review, 103(5): 1553-1597.

[9] Basu, S. (1996). "Procyclical Productivity: Increasing Returns or Cyclical Utilization?", Quarterly Journal of Economics, 111, 709-751.

[10] Blundell, R., R. Griffith, and F. Windmeijer, (2002) "Individual effects and dynamics in count data models", Journal of Econometrics 180, 113-131.

[11] Bonfiglioli, A., and G. Gancia (2008). "North-South Trade and Directed Technical Change," Journal of International Economics, 76, 276-296.

[12] Borota, T. (2012). "Innovation and imitation in a model of North-South trade", Journal of International Economics, 87, 365-376.

[13] Borota, T., and G. Impullitti (2014). "Innovation policy in a Global Economy: a European Perspective," mimeo.

[14] Burstein, A., and J. Vogel (2012), "International Trade, Technology, and the Skill Premium", mimeo.

[15] Cozzi, G. (2007). "The Arrow Effect under Competitive R\&D," The B.E. Journal of Macroeconomics, Berkeley Electronic Press, vol. 7(1)

[16] Chatterjee, S., D. Corbae, M. Nakajima, and V. Rios-Rull (2007). "A Quantitative Theory of Unsecured Consumer Credit with Risk of Default", Econometrica, Vol. 75, p. 1525-158. 
[17] Dinopoulos E. and P. Segerstrom. (1999). "A Schumpeterian Model of Protection and Relative Wages," American Economic Review 89, 450-472.

[18] Dinopoulos, E. and P. Tompson (1999). "Scale Effects in Schum- peterian Models of Economic Growth", Journal of Evolutionary Economics, 9(2), 157-85.

[19] Eaton, J., and S. Kortum (2007), "Innovation, Diffusion, and Trade", in Eytan Sheshinski, Robert J. Strom, and William J. Baumol, eds., Entrepreneurship, Innovation, and the Growth Mechanism of the Free-Enterprise Economies, Princeton University Press, 2007, 276-299.

[20] Epifani, P., and G. Gancia (2008) "The Skill Bias of World Trade", The Economic Journal, $118,927-960$.

[21] Feenstra, R., M. Obstfeld, and K. Russ (2012). "In Search of the Armington Elasticity", mimeo.

[22] Findlay, R., and H. Kierzkowski (1993). "International Trade and Human Capital: A Simple General Equilibrium Model", Journal of Political Economy, Vol. 91 (6), pp. 957978.

[23] Glass, A.J., (1997). "Product Cycles and Market Penetration," International EconomicReview 38, 865-891.

[24] Glass, A.J., and K. Saggi (1998). "International Technology Transfer and the Technology Gap," (with A. Glass), Journal of Development Economics 55, 369-398, 1998.

[25] Grossman G. M. and E. Helpman. (1991). Innovation and Growth in the Global Economy. Cambridge: MIT Press.

[26] Hall, B., Griliches, Z., and J, Hausman (1986), "Patents and R\&D: is there a Lag?," International Economic Review, 27 (1986), 265-83.

[27] Hsieh, C.T., and R. Ossa (2011), "A Global View of Productivity Growth in China," NBER Working Paper 16778.

[28] Impullitti, G. (2010). "International Competition and US R\&D Subsidies: a Quantitative Welfare Analysis," International Economic Review, Vol. 51, issue 4.

[29] Jones C. (1995). "Time Series Tests of Endogenous Growth Models", Quarterly Journal of Economics 110, 495-525.

[30] Jones, C., (2014), "The Macroeconomics of Piketty" Journal of Economic Perspectives, forthcoming. 
[31] Kortum, S. (1997). "Research, Patenting, and Technological Change," Econometrica, 65(6), 1389-1419.

[32] Kortum, S.,(1993) "Equilibrium R\&D Ratio and the Patent-R\&D Ratio: US Evidence," American Economic Review, P \& P 83, 450-457.

[33] Krusell, P., L. Ohanian, V. Rios-Rull, and G. L. Violante (2000): "Capital-Skill Complementarity and Inequality," Econometrica, 68:5, 1029-1054.

[34] Krusell, P. and T. Smith, (2014), "Is Piketty's 'Second Law of Capitalism' Fundamental?," Institute for International Economic Studies, manuscript.

[35] National Vital Statistics Reports (2010), Vol. 58, No. 21, June 28.

[36] Novy, D. (2013). "Gravity Redux: Measuring International Trade Costs with Panel Data" Economic Inquiry 51(1), January 2013, pp. 101-121.

[37] Mazzolari, E. and G. Ragusa (2013). "Spillovers from high- skill consumption to low-skill labor markets," Review of Economics and Statistics, March, 95(1): 74-86.

[38] Parello, C. (2008). "A North-South Model of Intellectual Property Rights Protection and Skill Accumulation". Journal of Development Economics, Vol. 85, Issues 1-2, pp. 253-281.

[39] Peretto, P. (1998). "Technological Change and Population Growth," Journal of Economic Growth, 3(4), 283-311.

[40] Piketty, T., (2014), "Capital in the Twenty-first Century", Harvard University Press, 2014.

[41] Piketty, T. and E. Saez, (2014), "Inequality in the Long Run", Science, 23, p. 838-842.

[42] Piketty, T. and G. Zucman, (2014), "Capital is Back: Wealth-Income Ratios in Rich Countries, 1700-2010", Quarterly Journal of Economics, 129 (3), pp. 1255-1310.

[43] Segerstrom, P. (1998) "Endogenous Growth Without Scale Effects," American Economic Review, 88, 1290-1310.

[44] Solow, R., (1956), " A Contribution to the Theory of Economic Growth", Quarterly Journal of Economics, 70, 1.

[45] Thoenig, M. and T. Verdier (2003). "A Theory of Defensive Skill Biased Innovation and Globalization", American Economic Review, vol. 93, 3, pp. 709-728, 2003.

[46] Yeaple, S. (2005). "A Simple Model of Firm Heterogeneity, International Trade, and Wages," Journal of International Economics, 2005, 65(1): 1-20. 